\title{
I - FLORÍSTICA E FITOSSOCIOLOGIA DE CAMPO NATURAL SOBRE BANCO DE CARVÃO E ÁREAS MINERADAS, RIO GRANDE DO SUL, BRASIL
}

\author{
Jairo José Zocche ${ }^{1}$
}

Maria Luiza Porto ${ }^{2}$

Recebido em 20-03-90. Aceito em 27-12-92.

\begin{abstract}
RESUMO: Realizaram-se na Mina Recreio, município de Butiá, RS, estudos florísticos e fitossociológicos em uma área de campo natural sobre banco de carvão e em áreas mineradas a céu aberto e revegetadas naturalmente. $\mathrm{Na}$ área de campo natural detectaram-se duas unidades de vegetação principais, denominadas de unidades diferenciais A (AXONOPUS - ANDROPOGON) e B (AXONOPUS - PIPTOCHAETIUM), ambas com suas respectivas subunidades de espécies possivelmente associadas. A variação espacial gradual verificada na área de campo natural configura-se principalmente pelo conjunto de condiçōes associadas à declividade e profundidade do lençol freático. Nas áreas mineradas II e III verificou-se que as unidades de vegetaçāo não se tinham delineado muito claramente e apresentavam características de vegetaçāo pioneira. $\mathrm{Na}$ área II evidenciou-se uma possível unidade de vegetaçāo PIPTOCHAETIUM AXONOPUS PURPUSII e na área III, PIPTOCHAETIUM - CYNODON. Verificou-se maior similaridade florística entre a área de campo natural e a área II, do que entre a III e o campo natural. As espécies presentes nas áreas mineradas apresentam certo grau de pioneirismo e tolerância em relaçāo ao conjunto de condiçōes extremas que enfrentam, devendo, portanto, ser as primeiras a ser testadas em trabalhos de recomposição de áreas mineradas.
\end{abstract}

Palavras-chave: Sucessāo secundária; Mineraçāo; Revegetação; Ecologia vegetal.

ABSTRACT: Studies were conducted at Mina Recreio, Butiá, RS, on floristic and phytosociological aspects in a natural grassland area laying on a coal bank and in

1 - Fundaçāo Educacional de Criciúma - FUCRI - Criciúma, Santa Catarina, BR. Caixa Postal D - 50 - 88805-350 Criciúma - SC.

2 - Centro de Ecologia e Departamento de Botânica Universidade Federal do Rio Grande do Sul - UFRGS - BR. Rua Paulo Gama sn². Prédio 25 - 90.049 - Porto Alegre RS. Pesquisador do CNPq - Processo $n^{\circledR} 305062 / 76$. 
surface coal mining areas which had beem naturally reclaimed. Two main vegetation units denominated differential units a (AXONOPUS - ANDROPOGON) and B (AXONOPUS - PIPTOCHAETIUM), both of them with their respective sub-units of possibly associated species, were detected in the natural grassland area. The gradual spatial variation, detected in the natural grassland area, is mainly characterized by the set of conditions associated with land declivity and water table depth. In both surface coal mining areas II and III the vegetation units were not clearly defined, but were characterized as primary areas. The vegetation unit PIPTOCHAETIUM - AXONOPUS PURPUSII was detected in area II and a vegetation unit PIPTOCHAETIUM - CYNODON in area III. A greater floristic similarity was verified between area II and natural grassland than between area III and natural grassland. The species detected in mining areas present certain degree of pioneerism and tolerance in relation to the set of extreme conditions which they faced, and should, therefore, be the first to be tested on mining area recomposition.

Key words: Secondary succession; Mining; Revegetation; Plant ecology.

\section{Introdução}

A mineração do carvão a céu aberto causa a degradação do solo. A demanda do carvão mineral aumentou em larga escala, do final da década de setenta até meados da década de oitenta, provocando, assim, aumento na extração desse mineral, gerando extensas áreas improdutivas no Sul do Brasil.

Alguns trabalhos preliminares de revegetação tem sido executados por algumas mineradoras, os quais tendem a tomar como base práticas agrícolas regulares, fracassando na maior parte das vezes, e nem sempre conduzidos por tempo suficiente. São raros porém os trabalhos experimentais que procuram enfatizar a degradação dos ecossistemas que se instalam sobre ou próximo às áreas de mineração de carvão, destacando-se os trabalhos preliminares de Pfadenhauer \& Winkler (1978) e Citadini-Zanette (1982).

A área escolhida para a realização do presente trabalho localiza-se na Mina Recreio no município de Butiá, RS, de propriedade da Companhia de Pesquisas de Lavras Minerais, COPELMI, onde atualmente a extração do carvão é feita pelo processo de mineração a céu aberto. Após a extração do mineral, as áreas mineradas sofrem um processo de recomposição, utilizando-se os rejeitos de mineração, bem como os do beneficiamento do carvão, para preencher a lavra, sendo esta recoberta finalmente por uma camada de argila de aproximadamente $0,30 \mathrm{~m}$ e uma camada de solo vegetal de aproximadamente $0,10 \mathrm{~m}$ originadas de áreas adjacentes, as quais estão sendo preparadas para serem mineradas.

A inexistência de trabalhos anteriores, que relacionem a recomposição vegetal das áreas mineradas do Sul do Brasil com os fatores ambientais que limitam o estabelecimento e desenvolvimento das comunidades vegetais levou ao desenvolvimento do presente trabalho, na tentativa de orientar adequadamente o manejo e utilização das áreas pós mineradas. 


\section{Material e Métodos}

Observações preliminares sobre a composição florística e do substrato, levaram a escolha de três subáreas de 1 ha cada, denominadas de área I (campo natural de pastoreio), área II (vegetação pioneira sobre área minerada e reencapada entre os anos de 1980/81, situada em uma elevação do terreno) e área III (vegetação pioneira sobre área minerada e reencapada entre os anos de 1979/80, situada em uma depressão do terreno).

Durante o período de abril de 1986 a março de 1987, realizaram-se várias excursões a fim de se coletar material botânico na área de campo natural e arredores, para identificação das espécies. O material coletado encontra-se depositado no herbário ICN, do Departamento de Botânica da Universidade Federal do Rio Grande do Sul.

Para o estudo fitossociológico adotou-se o método de abundância e cobertura, proposto por Braun-Blanquet (1950). Sortearam-se, em cada área de 1 ha, 26 pontos amostrais, por meio de coordenadas aleatórias $(\mathrm{x}, \mathrm{y})$, tomando-se o ponto sorteado como centro da unidade amostral de $1 \mathrm{~m}^{2}$.

Submeteram-se os dados de abundância e cobertura à análise fitossociológica, segundo o programa MANAGEMENT AND MULTIVARIATE ANALYSIS OF VEGETATION DATA (Wild \& Orloci, 1983), um pacote de programa de computador, composto por 12 programas e 7 arquivos de dados. Utilizaram-se para o processamento de dados fitossociológicos as sub-rotinas INIT, RESE, CLTR, TABS, AOCL e ORDB. A análise inicia com a entrada-padrão de dados no programa INIT (Initiation) que inicializa arquivos de dados, faz transformações, computa médias e freqüências e armazena coordenadas de dados para ordenações diretas.

A partir dos resultados de freqüência das espécies ocorrentes na amostragem fitossociológica da área $\mathrm{I}$, decidiu-se reduzir o número de espécies que seriam utilizadas na análise fitossociológica propriamente dita. Determinaram-se, primeiramente, conforme sugestões de Mueller-Dombois \& Ellenberg (1974), as espécies que estão presentes em alta percentagem de amostras, considerando-se como tal as que ocorreram em mais de $60 \%$ das unidades amostrais (freqüência absoluta maior do que 15,6 em 26 unidades amostrais).

Determinaram-se também as espécies de ocorrência eventual ou rara, considerando-se, assim, as espécies que ocorreram em menos de $10 \%$ das unidades amostrais (freqüência absoluta menor do que 3,0 em 26 unidades amostrais). Permaneceram então na análise fitossociológica somente as espécies que ocorreram entre 15 e 3 vezes em 26 unidades amostrais. Tais limites são estabelecidos arbitrariamente e Mueller-Dombois \& Ellenberg (1974) definiram como constância intermediária as classes de presença entre 60 e $10 \%$, que se aplicam às espécies presentes entre 15 e 3 vezes em 25 unidades amostrais. Outros limites podem ainda ser estabelecidos, dependendo das características da vegetação e do julgamento do pesquisador. 
A partir da seleção das espécies que ocorreram com freqüência absoluta entre 15 e 3 vezes na amostragem fitossociológica, segue-se a análise de dados, submetendo-se as unidades amostrais a uma análise de semelhança florística (similaridade), e as espécies à semelhança de distribuição espacial, por meio do programa RESE (resemblance), que gera vetores de matrizes de associação e coordenadas.

Baseando-se nos dados de abundância e cobertura das espécies selecionadas, classificaram-se as mesmas, arranjando-as em uma matriz (p x n) no programa RESE, onde o $\mathbf{p}$ representa as espécies nas linhas e $\mathbf{n}$ as unidades amostrais nas colunas, obtendo-se assim uma matriz de Distâncias Euclidianas (chord distance). Esta matriz foi o ponto de partida para a classificação das unidades amostrais e das espécies, através da análise de agrupamentos pelo critério da soma dos quadrados (sum of squares clustering) (Wild \& Orloci 1983), empregando-se o programa CLTR (cluster), que elabora e imprime dendrogramas e forma grupos de unidades amostrais que apresentam a máxima similaridade florística e grupos de espécies que apresentam a máxima similaridade de distribuição espacial.

Com base na ordenação das unidades amostrais e das espécies, gerada no programa CLTR, uma tabela rearranjada é impressa pelo programa TABS (Table), que imprime e computa também tabelas de constância e contingência. A análise de concentração executada pelo programa AOCL (concentration) é então efetuada sobre a tabela de contigência $(\mathrm{F})$, gerada no programa TABS, utilizando-se este programa para identificar os componentes principais da variação dos dados. Como na maior parte dos casos, o tamanho dos blocos da tabela rearranjada varia, as freqüências em $\mathrm{F}$ são ajustadas, a fim de igualar o tamanho, obtendo-se uma nova matriz.

O programa AOCL tem por finalidade extrair as variáveis canônicas, as quais redescrevem o espaço vegetacional em um menor número de dimensões e calcula os respectivos escores das colunas e das linhas, as quais são as posições dos grupos de unidades amostrais e dos grupos de espécies plotados no diagrama pelo programa ORDB (Ordination Diagram).

O Objetivo das técnicas de tabulação de unidades amostrais é a obtenção de uma tabela diferenciada, por meio da qual se tentará localizar as espécies que ocorrem juntas em várias unidades amostrais. Tais espécies são arranjadas em blocos, que tendem a ocorrer separados de outras espécies, ou blocos de espécies diferenciais.

Uma tabela diferenciada pode ser comparada com tabelas similares de vegetação de outras áreas ou regiões (Mueller-Dombois \& Ellemberg, 1974), permitindo, assim, o reconhecimento de tendências características de distribuição de espécies dentro de uma mesma província florística.

A comparação florística e fitossociológica da área de campo natural com as área mineradas adjacentes, obtida por meio de índices de similaridade e comparação tabular, permitirá, portanto, inferir o grau de similaridade entre as áreas e poderá ser utilizada como indicativo das tendências do desenvolvimento da vegetação e formação dos grupos de espécies nas áreas mineradas, uma vez que a 
proximidade das comunidades campestres naturais favorece a disseminação das espécies que integrarão a composição florística após a mineração. Verificou-se o grau de similaridade entre a área de campo natural e as demais áreas, por meio de dois índices de similaridade, SØrensen e Ellenberg (apud Mueller - Dombois \& Ellenberg, 1974).

Estabeleceu-se para cada área uma transeccional que acompanhasse o eixo de maior comprimento da mesma, para confecção do perfil e mapeamento da vegetação.

Determinou-se a profundidade do lençol freático na área de campo natural, pelo estudo dos furos de sonda de pesquisa da empresa mineradora.

\section{Resultados e Conclusões}

Chegou-se na área de campo natural e arredores, por meio do levantamento florístico, a um total de 37 famílias, 99 gêneros e 165 espécies, integrantes principalmente dos estratos herbáceo-arbustivo (Tabela 1). Dentre as espécies coletadas ocorreu uma citação nova para o estado do Rio Grande do Sul, Heliotropium lagoense (Warm.) Gurke. Do total de espécies registradas, ocorreram, na amostragem das três áreas, 31 famílias, 78 gêneros e 120 espécies, sendo que 60 espécies ocorreram exclusivamente na área de campo natural, 6 na área II e 4 a área III.

No inventário fitossociológico da área de campo natural, encontraram-se 29 famílias, 69 gêneros e 106 espécies (Tabela 2). Dentre estas famílias, destacam-se, pelo maior número de espécies presentes, as seguintes: Gramineae (15 gêneros e 29 espécies), Compositae (14 gêneros e 21 espécies) e Cyperaceae (5 gêneros e 13 espécies). Estas três famílias contribuem com 49,27 dos gêneros e com 59,43\% das espécies encontradas na amostragem fitossociológica desta área.

Boldrini \& miotto (1987), num estudo similar em local próximo, detectaram, em 16 amostras de $0,25 \mathrm{~m}^{2}$ cada, a presença de 112 espécies pertencentes principalmente às famílias Compositae, Gramineae, Leguminosae, Cyperaceae e Rubiaceae.

Pillar (1988), estudando fatores abióticos ambientais relacionados à variação da vegetação de um campo natural, em área próxima aos trabalhos de Boldrini \& Miotto (op.cit), encontrou em uma área de 30 ha, amostrada por meio de 60 quadrados de $0,25 \mathrm{~m}^{2}$ cada, 160 espécies, pertencentes a sete tipos de comunidades, condicionadas por diferentes fatores ambientais.

Em classificações baseadas no critério florístico, isto é, composição de espécies e suas variações quantitativas, o problema de separar a vegetação dentro de unidades amostrais pode ser resolvido depois que uma lista de todas as espécies de todas as unidades amostrais for transferida para uma tabela simples (MuellerDombois \& Ellenberg, 1974).

Das 106 espécies ocorrentes no levantamento fitossociológico (Tabela 2), selecionaram-se 58 com classe de constância entre 60 e $10 \%$ (Tabela 3). Baseada nos dados de abundância e cobertura destas 58 espécies, obteve-se uma matriz de 
Tabela 1 - Lista das 37 famílias botânicas, com seus respectivos gêneros e espécies encontradas na área de campo natural e arredores, Mina Recreio, Butiá - RS.

1 - AMARANTHACEAE

Pfaffia tuberosa (Spreng.) Hicken

2 - AMARYLLIDACEAE

Habranthus cf. tubispathus (L. Herr) Traub.

3 - BORAGINACEAE

Echium cf. plantagineum $\mathrm{L}$.

Heliotropium lagoense (Warm.) Gurke

4 - BRYACEAE

Bryum sp.

5 - CAMPANULACEAE

Pratia hederacea (Cham.) G. Don

6 - COMPOSITAE

Acanthospermum australe (Loef1.) O.K.

Aspilia montevidensis (Spreng.) O.K.

Aster cf. squamatus (Spreng.) Hieron.

Baccharis articulata (Lam.) Pers.

Baccharis dracunculifolia DC.

Baccharis spicata (Lam.) Baill.

Baccharis trimera (Less.) DC.

Chevreulia sarmentosa (Pers.) Blake

Conyza sp.

Elephantopus mollis H.B.K.

Eupatorium inulaefolium H.B.K.

Eupatorium laevigatum Lam.

Eupatorium grande Sch. Bip.

Eupatorium sp.

Facelis retusa (Lam.) Sch. Bip.

Gamochaeta cf. americana (Mill.) Weddell

Gamochaeta cf. filaginea (DC.) Cab.

Gamochaeta spicata (Lam.) Cabr.

Hipochoeris sp.

Micropsis spathulata (Pers.) Cab.

Noticastrum marginatum (H.B.K.) Cuat.

Pluchea sagittalis (Lam.) Cab.

Pterocaulon lanatum DC. 
Cont. Tabela 1

Pterocaulon polystachyum DC.

Senecio brasiliensis (Spreng.) Less.

Senecio cisplatinus Cabr.

Senecio heterotrichus DC.

Senecio leptolobulos DC.

Senecio selloi (Spreng.) DC.

Solidago chilensis Meyen.

Soliva pterosperma (Juss.) Less.

Taraxacum officinale weher ex Wiggers

Vernonia sp.

Vernonia nudiflora Less.

Vernonia sellowii Less.

7 - CONVOLVULACEAE

Dichondra sericea $\mathrm{Sw}$.

Evolvulus sericeus Sw.

Ipomoea cf. triloba Thumb.

8 - CYPERACEAE

Carex phalaroides Künth

Cyperus cayennensis (Lam.) Britton

Cyperus obtusifolius Presl.

Cyperus polystachyus Rottb.

Cyperus laetus Künth

Cyperus sesquiflorus (Torrey) Mattf. et Künth

Cyperus sp.

Eleocharis $\mathrm{cf}$. bonariensis Ness

Eleocharis minima Künth

Eleocharis cf. sellowiana Künth

Eleocharis $\mathrm{cf}$. viridans Künth

Fimbristylis cf. dichotoma (L.) Vahl

Fimbristylis sp.

Fimbristylis sp. 1

Rhynchospora britonii Gale

Rhynchospora rugosa (Vahl) Gale

Rhynchospora tenuis Link.

Rhynchospora sp.

9 - DROSERACEAE

Drosera sp. 
Cont. Tabela 1

10 - EUPHORBIACEAE

Croton gnaphali Baill.

Euphorbia papillosa St. Hil.

11 - GRAMINEAE

Agrostis montevidensis Sprengel ex Nees

Andropogon lateralis Nees

Andropogon selloanus (Hack.) Hack.

Aristida jubata (Arech.) Herter

Aristida laevis (Nees) Künth

Axonopus affinis Chase

Axonopus purpusii (Mez.) Chase

Brachiaria plantaginea (Link.) Hitchc.

Briza Minor L.

Briza subaristata Doell

Coelorhachis selloana (Hack.) Camus

Cynodon dactylon (L.) Pers.

Digitaria ciliaris (H.B.K) Henrard

Eleusine tristachya (Lam.) Lam.

Eragrostis airoides Nees

Eragrostis bahiensis (Schrad ex. Schultes) Schultes

Eragrostis lugens Nees

Eragrostis neesii Trin.

Eragrostis polytricha Nees

Panicum decipiens Nees

Panicum demissum Trin.

Panicum gouinii Fournier

Panicum milioides Nees ex Trin.

Panicum sabulorum Lam.

Paspalum dilatatum Poir.

Paspalum nicorae Parodi

Paspalum notatum $\mathrm{Fl}$.

Paspalum paucifolium J. Sw.

Paspalum plicatulum Michx.

Paspalum pumilum Nees

Paspalum urvillei Steudel

Piptochaetium montevidense (Spreng.) Parodi

Rhynchelytrum repens (Wild.) Hubbard

Setaria geniculata (Lam.) Beauv.

Sporobulus indicus (L.) R. B. 
Cont. Tabela 1

\section{2 - HYPERICACEAE}

Hypericum brasiliense Choisy

13 - HYPOXIDACEAE

Hypoxis decumbens $\mathrm{L}$.

14 - IRIDACEAE

Herbertia pulchella Sw.

Sizyrinchium sp.

Sizyrinchium sp. 1

Sizyrinchium vaginatum Spreng.

15 - ISOETACEAE

Isoetes $\mathrm{sp}$.

16 - JUNCACEAE

Juncus bufonius L.

Juncus capillaceus Lam.

Juncus cf. dombeyanus Gay

Juncus cf. microcephalus H.B.K.

Juncus cf. sellowianus Künth

Juncus sp.

17 - LABIATAE

Hyptis breviptis Poit

18 - LEGUMINOSAE

Aeschynomene sp.

Arachis burkartii Handro

Cassia sp.

Crotalaria sp.

Desmodium incanum DC

Desmanthus virgatus (L.) Willd.

Mimosa bimucronata (DC) O. Kuntze

Stylosanthes leiocarpa Vog.

19 - LYTHRACEAE

Cuphea cf. acinifolia St. Hil.

Cuphea carthagenensis (Jacq.) Macbride 
Cont. Tabela 1

20 - MALVACEAE

Sida rhombifolia $\mathrm{L}$.

Sida spinosa $\mathrm{L}$.

21 - MELASTOMATACEAE

Tibouchina gracilis (Bonpl.) Cogn.

22 - ONAGRACEAE

Ludwigia cf. elegans (Camb.) Hara

Ludwigia cf. peruviana (L.) Hara

23 - OPHIOGLOSSACEAE

Ophioglossum crotalophoroides Walt.

24 - ORCHIDACEAE

Habenaria sp.

25 - OXALIDACEAE

Oxalis articulata Savigny

Oxalis cf. hispidula zuccarinini

Oxalis perdicaria (Molina) Bertero

Oxalis cf. conorrhiza (Feuillée) Jacq.

Oxalis sp.

26 - PLANTAGINACEAE

Plantago australis Lam.

Plantago myosuros Lam.

27 - POLYGALACEAE

Polygala molluginifolia St. Hil.

Polygala cf. linoides Poir.

28 - POLYGONACEAE

Polygonum setaceum Baldwim

29 - PRIMULACEAE

Anagallis minima (L.) E.H.L.

30 - RUBIACEAE

Borreria capitata (R. et P.) DC

Borreria equisetoides Cham. et Schlecht. 
Cont. Tabela 1

Diodia cf. dasycephala Cham. et Schlecht.

Emmeorrhiza umbellata (Spreng.) Schum.

Mitracarpus megapotamicus (Spreng.) O. Kuntze

Relbunium hirtum (Lam.) K. Schum.

Richardia brasiliensis $\mathrm{Gomez}$

Richardia humistrata (Cham. et Schlecht.) Steud.

31 - SCROPHULARIACEAE

Buchnera integrifolia Larrañnga

Gerardia communis Cham. et Schlecht.

Gratiola peruviana $\mathrm{L}$.

Mecardonia tenella (Cham. et Schlecht.) Pennell

Linaria texana Schlecht.

32 - SOLANACEAE

Solanum cf. nudiflorum Jacq.

Solanum sisymbriifolium Lam.

Petunia sp.

33 - SPHAGNACEAE

Sphagnum sp.

34 - TURNERACEAE

Turnera sidoides $\mathrm{L}$.

35 - UMBELLIFERAE

Centella hirtella Nannf.

Eryngium elegans Cham. et Schlecht.

Eryngium pandanifolium Cham. et Schlecht.

Hydrocotyle ranunculoides L.F.

36 - VERBENACEAE

Lantana sp.

37 - VIOLACEAE

Hybanthus parviflorus (Mutis) Baill. 
Tabela 2 - Abundância e cobertura das 106 espécies registradas nas 26 unidades amostrais na área de campo natural, Mina Recreio, Butiá - RS, estimada pela escala de abundância e cobertura de Braun-Blanquet (1950) ${ }^{1}$.

\section{UNIDADES AMOSTRAIS}

$\begin{array}{lllllllllllllllll}1 & 1 & 1 & 1 & 1 & 1 & 1 & 1 & 1 & 1 & 2 & 2 & 2 & 2 & 2 & 2 & 2\end{array}$

ESPÉCIES

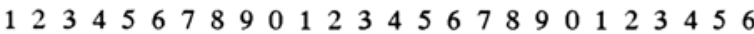

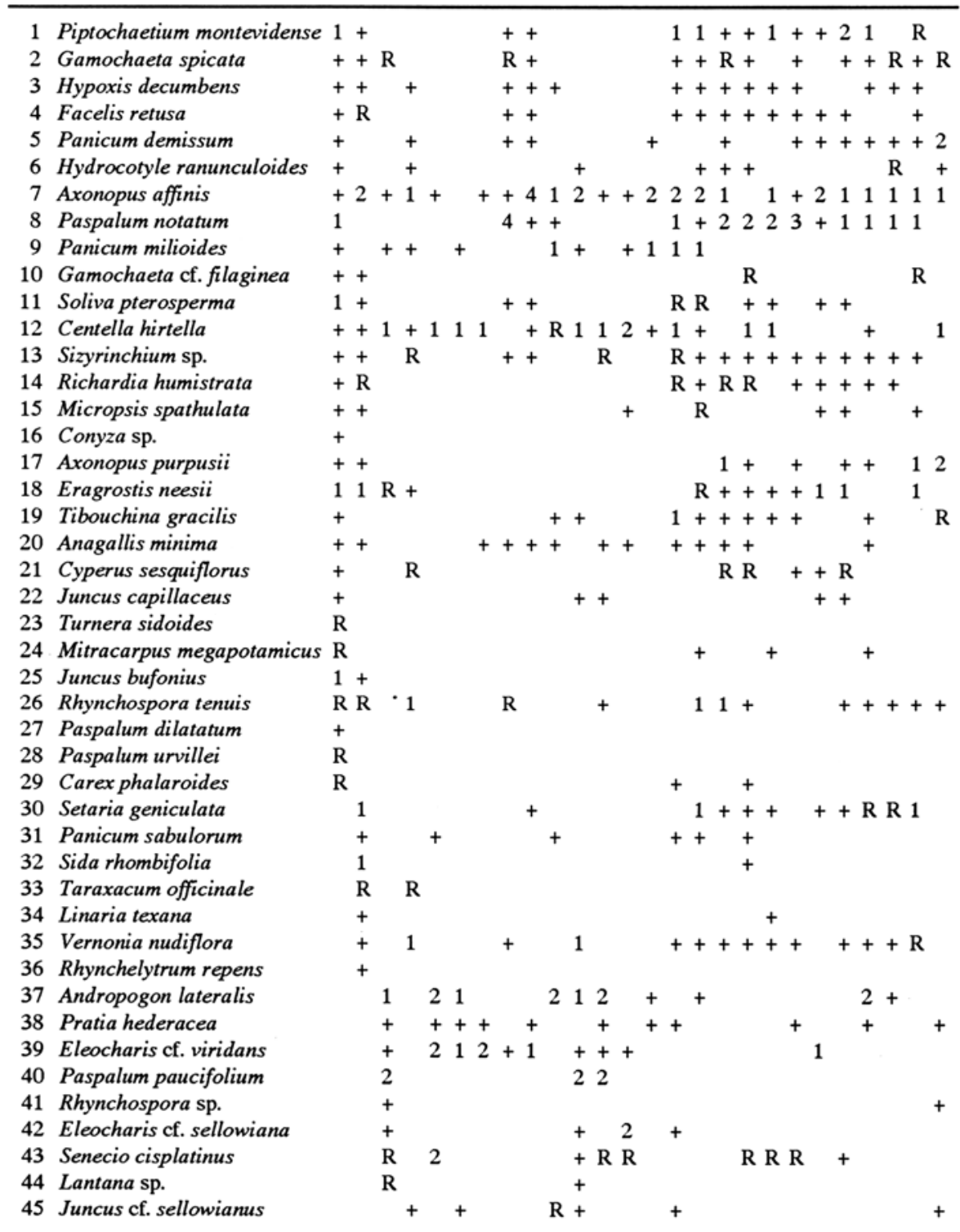


Cont. Tabela 2

46 Aristida jubata

47 Juncus cf. microcephalus

48 Mecardonia tenella

49 Drosera sp.

50 Oxalis perdicaria

51 Juncus $\mathrm{sp}$.

52 Baccharis articulata

53 Pfaffia tuberosa

54 Rhynchospora rugosa

55 Paspalum pumilum

56 Senecio heterotrichus

57 Isoetes sp.

58 Gamochaeta cf. americana

59 Panicum decipiens

60 Rhynchospora britonii

61 Elephantopus mollis

62 Plantago australis

63 Chevreulia sarmentosa

64 Oxalis cf. hispidula

65 Sporobulus indicus

66 Senecio brasiliensis

67 Evolvulus sericeus

68 Dichondra sericea

69 Desmodium incanum

70 Relbunium hirtum

71 Oxalis sp.

72 Cuphea carthagenensis

73 Ophioglossum crotalophoroides

74 Eleocharis cf. bonariensis

75 Fimbritylis cf. dichotoma

76 Cynodon dactylon

77 Gratiola peruviana

78 Cyperus obtusifolius

79 Eleocharis minima

80 Ludwigia cf. elegans

81 Eupatorium inulaefolium

82 Hyptis breviptis

83 Panicum gouinii

84 Sphagnum sp.

85 Paspalum nicorae

86 Plantago myosuros

87 Borreria equisetoides

88 Habenaria sp.

89 Vernonia sp.

90 Stylosanthes Leiocarpa

91 Andropogon selloanus

92 Arachis burkartii
1

$1 \mathrm{R}$

$\mathrm{R}$

$+\mathrm{R} R$
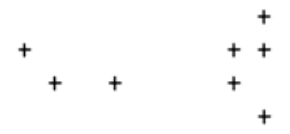

R

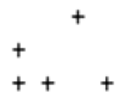

$+$

$+$

$\mathrm{R}$

$\mathrm{R}$

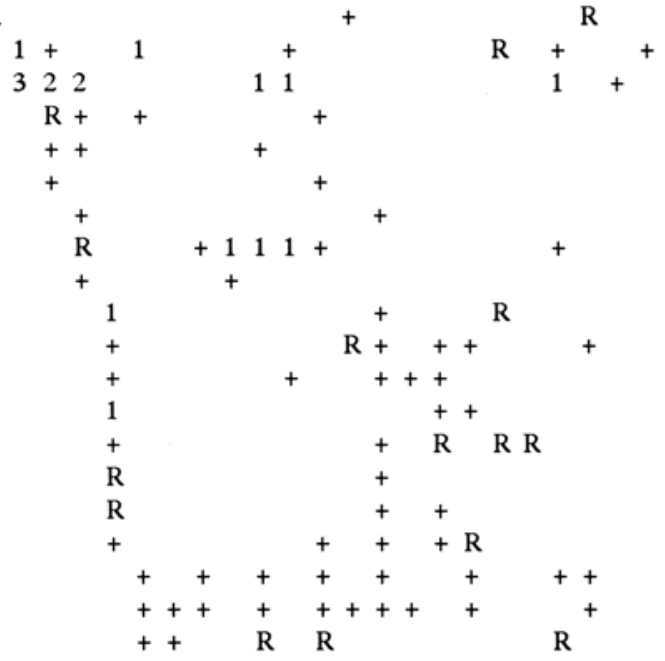

R $1++1+1 \quad 3$ $++$

$+$

R

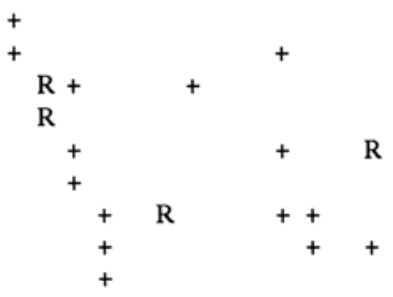


Cont. Tabela 2

UNIDADES AMOSTRAIS

$\begin{array}{lllllllllllllllll}1 & 1 & 1 & 1 & 1 & 1 & 1 & 1 & 1 & 1 & 2 & 2 & 2 & 2 & 2 & 2 & 2\end{array}$

ESPÉCIES $\begin{array}{llllllllllllllllllllllllll}1 & 2 & 3 & 4 & 5 & 6 & 7 & 8 & 9 & 0 & 1 & 2 & 3 & 4 & 5 & 6 & 7 & 8 & 9 & 0 & 1 & 2 & 3 & 4 & 5 & 6\end{array}$

93 Paspalum plicatulum

94 Herbertia pulchella

95 Aspilia montevidensis

96 Briza minor

97 Baccharis trimera

98 Pterocaulon lanatum

99 Juncus cf. dombeyanus

100 Agrostis montevidensis

101 Aristida laevis

102 Eragrostis polytricha

103 Eleusine tristachya

104 Digitaria ciliaris

105 Cyperus cayennensis

106 Senecio selloi

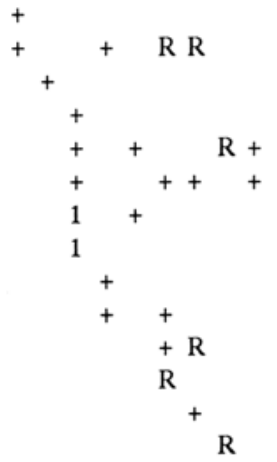

1 - Escala de abundância e cobertura de Braun-Blanquet (1950).

$\mathrm{R}=$ planta que ocorre apenas uma vez na unidade amostral, com cobertura muito baixa.

$+=$ planta escassa com valor de cobertura muito baixo.

1 = planta abundante porém com valor de cobertura baixo.

2 = planta muito abundante com cobertura escassa ou cobrindo entre $1 / 10$ e $1 / 4$ da superfície estudada.

3 - cobrindo entre $1 / 4$ e $1 / 2$ da superfície, com qualquer número de indivíduos.

4 - cobrindo entre $1 / 2$ e $3 / 4$ da superfície, com qualquer número de indivíduos.

5 - cobrindo mais de $3 / 4$ da superfície, com qualquer número de indivíduos.

- Espaços em branco, indicam ausência na unidade amostral.

Tabela 3 - Abundância e cobertura das 58 espécies que ocorreram com freqüência entre 60 e $10 \%$ ( 15 e 3 vezes) em 26 unidades amostrais na área de campo natural, Mina Recreio, Butiá - RS.

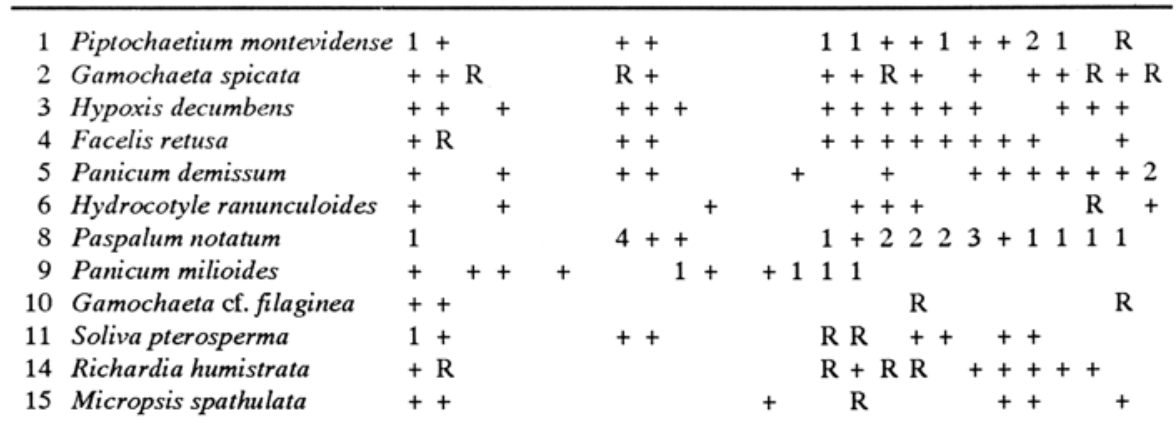




\begin{tabular}{|c|c|c|c|c|c|c|c|c|c|c|c|c|c|c|c|}
\hline 17 & Axonopus purpusii & ++ & & & & & & & & $1+$ & + & + & ++ & & \\
\hline 18 & Eragrostis neesii & $11 \mathrm{R}$ & + & & & & & & & ++ & ++ & +11 & 1 & 1 & \\
\hline 9 & Tibouchina gracilis & + & & & & ++ & & & $1+$ & ++ & ++ & & + & & $\mathrm{R}$ \\
\hline 0 & Anagallis minima & ++ & & & +++ & ++ & + & + & ++ & ++ & & & + & & \\
\hline 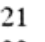 & Cyperus sesquiflorus & + & $\mathrm{R}$ & & & & & & & R R & & $+\mathrm{R}$ & $\mathrm{R}$ & & \\
\hline 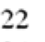 & Juncus capillaceus & + & & & & & ++ & & & & & ++ & + & & \\
\hline 4 & Mitracarpus megapotamicus & $\mathrm{R}$ & & & & & & & + & & + & & + & & \\
\hline 6 & Rhynchospora tenuis & R R & 1 & & $\mathrm{R}$ & & + & & 1 & $1+$ & & & ++ & ++ & \\
\hline 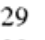 & Carex phalaroides & $\mathrm{R}$ & & & & & & & + & + & & & & & \\
\hline 0 & Setaria geniculata & 1 & & & & + & & & 1 & ++ & + & ++ & $+\mathrm{R}$ & R 1 & \\
\hline 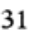 & Panicum sabulorum & + & + & & & + & & & ++ & + & & & & & \\
\hline 5 & Vernonia nudiflora & + & 1 & & + & & 1 & & ++ & ++ & ++ & . & ++ & $+\mathrm{R}$ & \\
\hline 37 & Andropogon lateralis & 1 & 2 & 1 & & 21 & 12 & + & $+\quad+$ & & & & 2 & + & \\
\hline 8 & Pratia hederacea & + & + & ++ & + & & + & & ++ & & + & & + & & + \\
\hline 9 & Eleocharis $\mathrm{cf}$. viridans & + & 2 & 12 & $2+1$ & & ++ & + & & & & 1 & & & \\
\hline 9 & Paspalum paucifolium & 2 & & & & & 22 & & & & & & & & \\
\hline 2 & Eleocharis cf. sellowiana & + & & & & & + & 2 & + & & & & & & \\
\hline 43 & Senecio cisplatinus & $\mathrm{R}$ & 2 & & & & $+\mathrm{R}$ & $\mathrm{R}$ & & & R R & & + & & \\
\hline 45 & Juncus cf. sellowianus & & & + & & $\mathrm{R}+$ & + & & + & & & & & & \\
\hline 47 & Juncus cf. microcephalus & & $1 \mathrm{R}$ & & & & & & & + & $\mathrm{R}$ & & & + & \\
\hline 8 & Mecardonia tenella & & $\mathrm{R}$ & & + & & & & & + & & & + & & \\
\hline 49 & Drosera sp. & & $+\mathrm{R}$ & $\mathrm{R}$ & & + & + & & + & & & & + & ++ & \\
\hline 53 & Pfaffia tuberosa & & $\mathrm{R}$ & & & & & & + & & & & & $\mathrm{R}$ & \\
\hline 54 & Rhynchospora rugosa & & 1 & + & 1 & & & + & & & & $\mathrm{R}$ & + & + & \\
\hline 55 & Paspalum pumilum & & 3 & 22 & & & & 11 & & & & & 1 & + & \\
\hline 56 & Senecio heterotrichus & & & $\mathrm{R}+$ & + & & & & + & & & & & & \\
\hline 57 & Isoetes sp. & & & ++ & & & & + & & & & & & & \\
\hline 60 & Rhynchospora britonii & & & $\mathrm{R}$ & R & & +1 & 11 & + & & & & + & & \\
\hline 62 & Plantago a & & & & 1 & & & & & + & & $\mathrm{R}$ & & & \\
\hline 63 & Chevreulia & & & & + & & & & & + & ++ & & & + & \\
\hline 64 & Oxalis & & & & + & & & + & & ++ & + & & & & \\
\hline 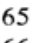 & Spor & & & & 1 & & & & & & ++ & & & & \\
\hline 66 & iensis & & & & + & & & & & + & $\mathrm{R}$ & R R & & & \\
\hline 68 & Dichondra sericea & & & & $\mathrm{R}$ & & & & & + & + & & & & \\
\hline 69 & Desmodium incanum & & & & + & & & & + & + & $+\mathrm{R}$ & & & & \\
\hline 70 & Relbunium hirtum & & & & + & & + & + & + & + & + & & + & + & \\
\hline 71 & Oxalis sp. & & & & + & ++ & + & + & ++ & ++ & & & & + & \\
\hline 72 & Cuphea carthagenensis & & & & & + & & $\mathrm{R}$ & $\mathrm{R}$ & & & & $\mathrm{R}$ & & \\
\hline 74 & Eleocharis cf. bonariensis & & & & & 1 & & + & +1 & +1 & & & & 3 & \\
\hline 86 & Plantago myosuros & & & & & & & & $R+$ & & + & & & & \\
\hline 88 & Habenaria sp. & & & & & & & & + & & & & + & & \\
\hline 90 & Stylosanthes leiocarpa & & & & & & & & + & $\mathrm{R}$ & & & + & + & \\
\hline 91 & Andropogon selloanus & & & & & & & & + & & & & & + & \\
\hline 94 & Herbertia pulchella & & & & & & & & + & & + & & $\mathrm{R}$ & & \\
\hline 97 & Baccharis trimera & & & & & & & & & + & + & & & $R+$ & \\
\hline 98 & Pterocaulon lanatum & & & & & & & & & + & & ++ & & + & \\
\hline
\end{tabular}


distâncias euclidianas, entre as unidades amostrais. Com base nesta matriz, obteve-se, pela análise de agrupamentos, o dendrograma de variância mínima entre as unidades amostrais, conforme mostra a Figura 1.

Submeteram-se as espécies à mesma rotina de análise a que foram submetidas as unidades amostrais da área de campo natural, obtendo-se assim o dendrograma de espécies (Figura 2). Neste, as espécies estão reunidas em grupos, de acordo com sua distribuição na área amostral, isto é, obteve-se uma classificação das espécies que tendem a ocorrer juntas em um habitat específico, formando grupos de espécies.

Com a ordenação das unidades amostrais e das espécies e com sua classificação nos respectivos grupos definidos, cruzando-se as informações, gerou-se uma tabela estruturada (Tabela 4). Pela análise desta tabela, na área de campo natural delinearamse duas unidades vegetacionais principais, denominadas de $\mathrm{A}$ e $\mathrm{B}$, com suas respectivas subunidades e subgrupos associados.

A unidade diferencial A formou-se, preferencialmente, na parte de baixada da área, onde as curvas de nível atingem as cotas de $66,0 \mathrm{~m}$. O solo é muito úmido, e o lençol freático chega a uma profundidade média de aproximadamente $0,30 \mathrm{~m}$ (Figura 3). Esta unidade está composta pelas espécies Paspalum pumilum, Eleocharis cf. viridans, Isoetes sp., Drosera sp., Andropogon lateralis, Rhynchospora rugosa, Pratia hederacea e Senecio cisplatinus.

A unidade diferencial B delineou-se na parte da área com altitude mais elevada, entre as curvas de nível 69,0 e $66,5 \mathrm{~m}$. Nesta parte o campo apresenta o solo mais seco e mais arenoso do que na parte de baixada, e o lençol freático atinge profundidade entre 1,5 e 3,0 m. Eragrostis neesii, Richardia humistrata, Facelis retusa, Piptochaetium montevidense, Gamochaeta spicata, Soliva pterosperma e Setaria geniculata são as espécies que compõem esta unidade.

A unidade diferencial A apresentou uma subunidade denominada A1, composta pelas espécies Paspalum paucifolium, Juncus capillaceus, Rhynchospora britonii, Eleocharis cf. sellowiana, Juncus $\mathrm{cf}$. sellowianus e Panicum milioides. Esta subunidade localiza-se na porção da área onde o lençol freático atinge a profundidade de $0,10 \mathrm{~m}$.

A unidade diferencial B apresentou duas subunidades B1 e B2, sendo B1 composta pelas espécies Oxalis sp, Paspalum notatum, Relbunium hirtun, Vernonia nudiflora, Hypoxis decumbens e Tibouchina gracilis.

A subunidade B2 apresenta-se composta pelas espécies Axonopus purpusii, Panicum demissum, Rhynchospora tenuis, Hydrocotyle ranunculoides e Juncus cf. microcephalus. Tal subunidade delineou-se, assim como a unidade diferencial $\mathrm{B}$, na parte mais elevada da área. No entanto, algumas de suas espécies tiveram abundância $\mathrm{e}$ cobertura mais expressivas na faixa de transição entre o campo com solo seco e o campo de baixada com solo úmido.

A subunidade B1, por sua vez, é composta por dois subgrupos de espécies B1 (I) e B1 (II), os quais delinearam-se na porção da área com altitude r.ais elevada e solo seco. O subgrupo B1 (I) está composto por Panicum sabulorum, Carex phalaroides, Cuphea carthagenensis, Anagallis minima e Senecio heterotrichus.

O subgrupo B1 (II) mostra-se composto pelas espécies Senecio brasiliensis, Plantago australis, Sporobulus indicus, Chevreulia sarmentosa, Desmodium incanum, Dichondra sericea e Oxalis cf. hispidula. 


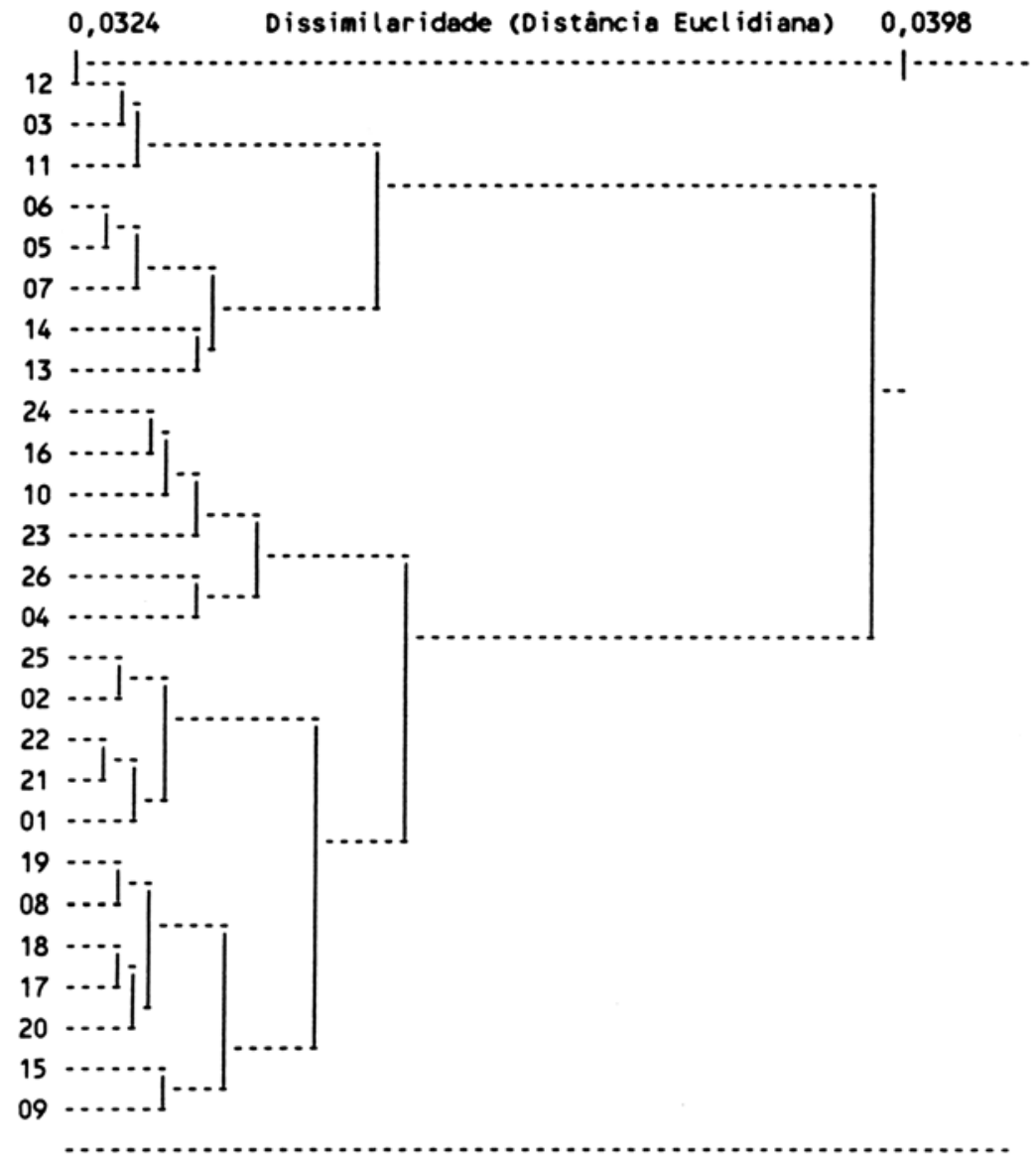

Figura 1 - Dendrograma de classificação das unidades amostrais da área de campo natural, Mina Recreio, Butiá - RS, obtido pela análise de agregação aplicada à Tabela 3 .

A subunidade B2 apresentou também um subgrupo B2 (I), composto pelas espécies Pterocaulon lanatum, Baccharis trimera, Micropsis spathulata, Gamochaeta cf. filaginea e Cyperus sesquiflorus. Este grupo de espécies tende ao campo com condições de solo semelhantes ao da unidade diferencial B, apresentando maior freqüência de suas espécies exatamente a partir dos limites da faixa de transição entre o campo seco e o campo úmido.

Observando-se a distribuição dos grupos de amostras na tabela estruturada 4, a distribuição das espécies dentro destes grupos sugere que a umidade (produndidade do lençol freático) seja o fator preponderante na separação destes grupos. Mueller-Dombois \& Ellenberg (1974) citaram que combinações similares de espécies ocorrem em habitats com condições similares, em regiōes geograficamente separadas ou não.

Na área de campo natural, portanto, a separação dos grupos de unidades amostrais, bem como a composição de espécies, vem refletir o que havia sido pressuposto no 


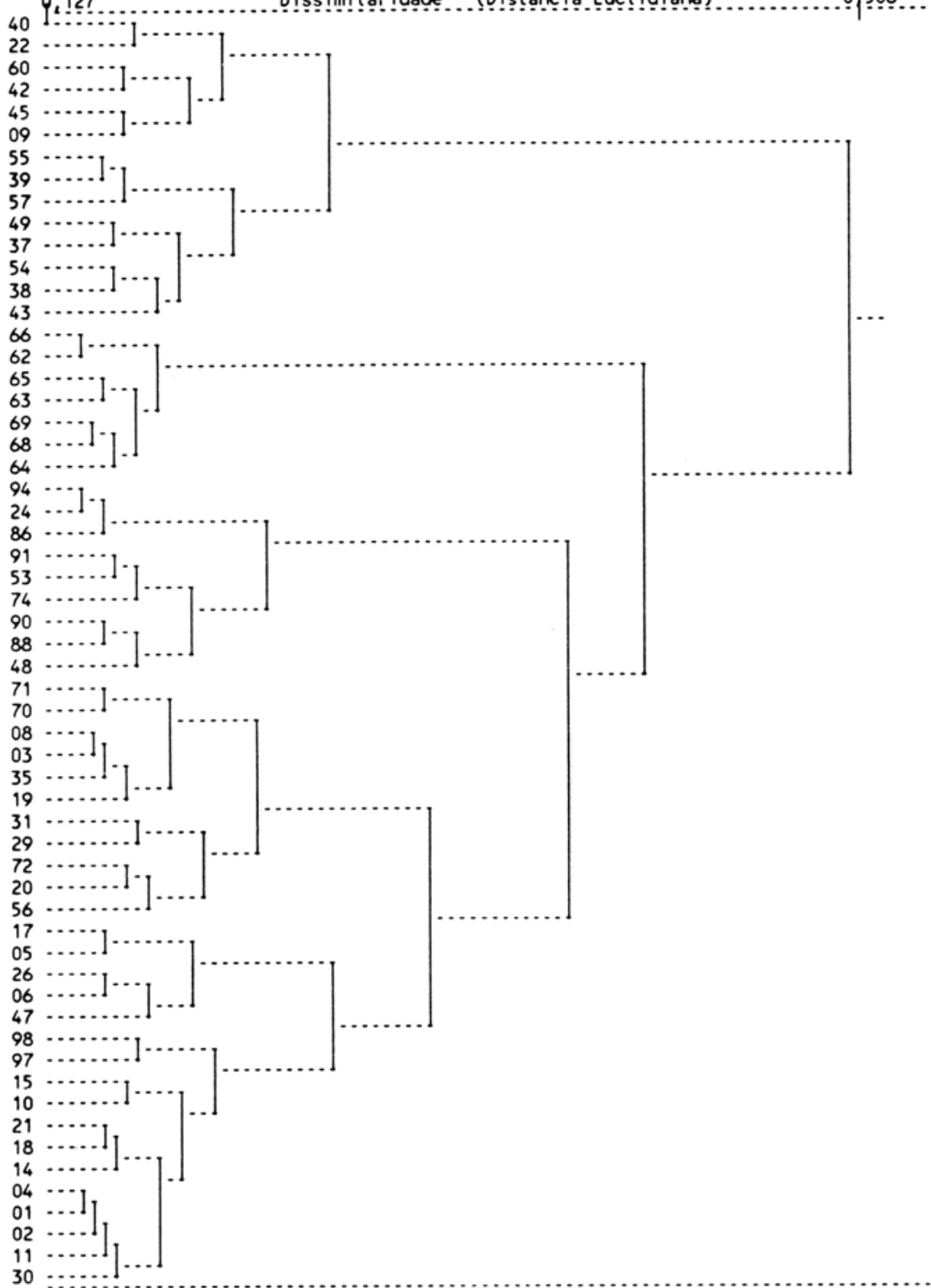

Figura 2 - Dendrograma de classiticação das espécies da área de campo natural, Mina Recreio, Butiá - RS, obtido pela análise de agregação aplicada à Tabela 3.

momento da escolha da área amostral, isto é, em função da topografia do terreno, havia a separação de dois tipos principais de comunidades, os quais refletiram-se na tabela estruturada 4. 
Tabela 4 - Abundância e cobertura das 58 espécies mais importantes da área de campo natural, Mina Recreio, Butiá - RS, ordenadas juntamente com as unidades amostrais, pelos grupos gerados na análise de agregação. Blocos pontilhados evidenciam espécies que ocorreram na área de transição.

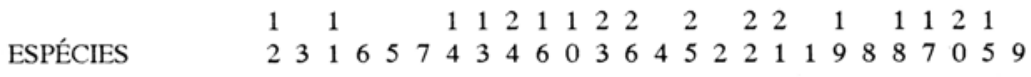

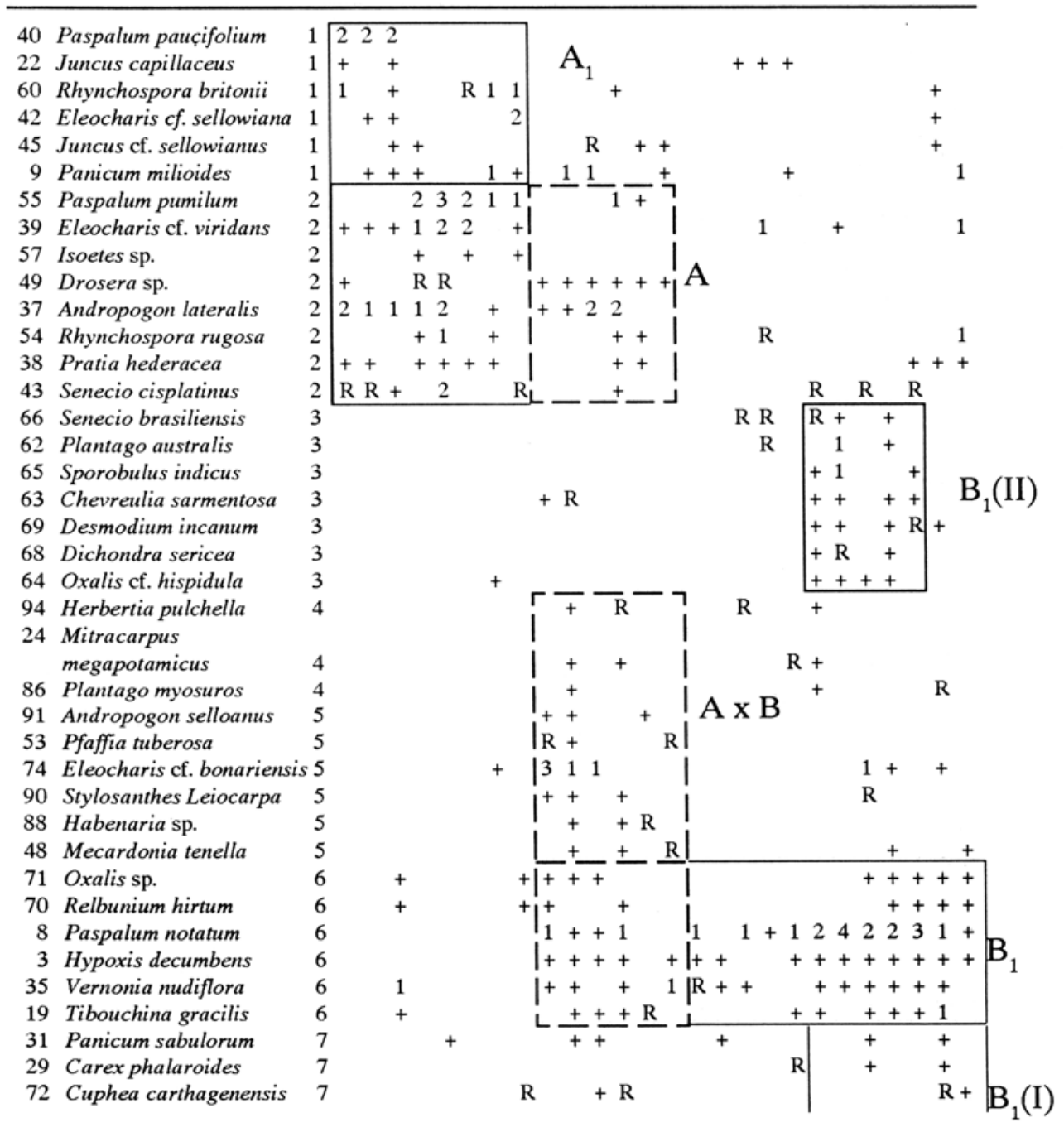


Cont. Tabela 4

GRUPOS DE UNIDADES AMOSTRAIS

$\begin{array}{llllllllllllllllllllllllll}1 & 1 & 1 & 2 & 2 & 2 & 3 & 3 & 3 & 3 & 3 & 3 & 4 & 4 & 4 & 4 & 4 & 5 & 5 & 5 & 5 & 5 & 5\end{array}$

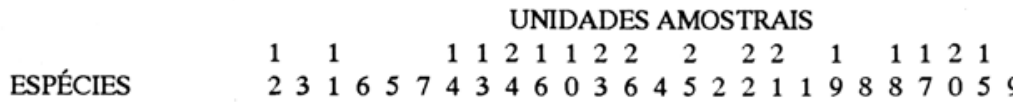

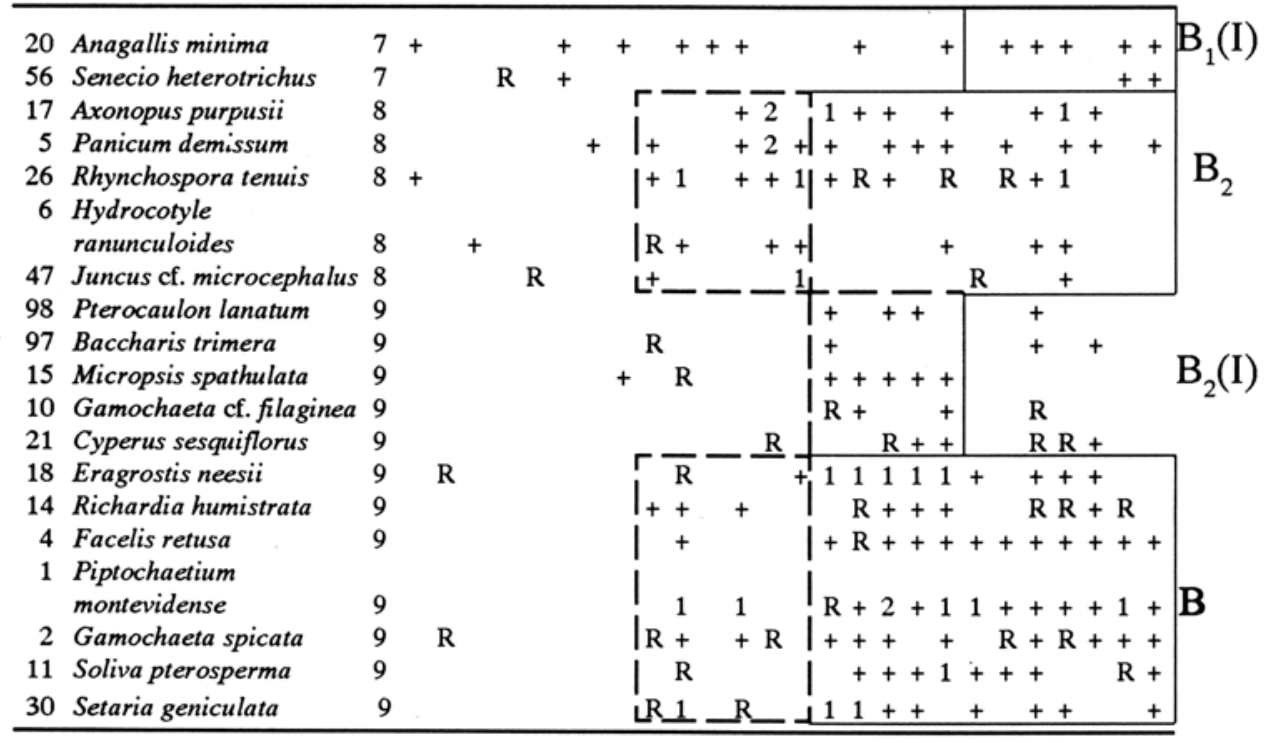

Considerando-se a área de campo natural em um gradiente de umidade, as unidades amostrais pertencentes à unidade diferencial $\mathrm{A}$ e sua respectiva subunidade estão localizadas no extremo mais úmido, tendendo ao campo alagado. Tal fato evidencia-se pela presença preferencial de Paspalum paucifolium, formando manchas densas e homogêneas. Tal espécie está caracterizando a própria subunidade A1. As espécies que compõem a unidade diferencial A também se distribuem na área de campo úmido; porém o lençol freático não chega tão próximo à superfície como no caso da subunidade A1. Esta região está ocupada preferencialmente, por Paspalum pumilum e Eleocharis $\mathrm{cf}$. viridans, esta última, embora penetre tanto em ambientes com alto grau de umidade quanto em mais secos, apresentou maior abundância e cobertura exatamente nesta faixa, onde o lençol freático está a $0,30 \mathrm{~m}$ de profundidade. Andropogon lateralis foi a espécie que evidenciou maior abundância e cobertura dentro da unidade diferencial A. Pratia hederacea, embora tenha apresentado distribuição ampla dentro da unidade $\mathrm{A}$, ocorrendo inclusive em unidades amostrais da unidade diferencial $\mathrm{B}$, evidenciou maior abundância $\mathrm{e}$ cobertura nos ambientes mais úmidos. Ao contrário, Drosera $\mathrm{sp}$, que também apresentou ampla distribuição nesta unidade, concentrou-se mais na faixa de 

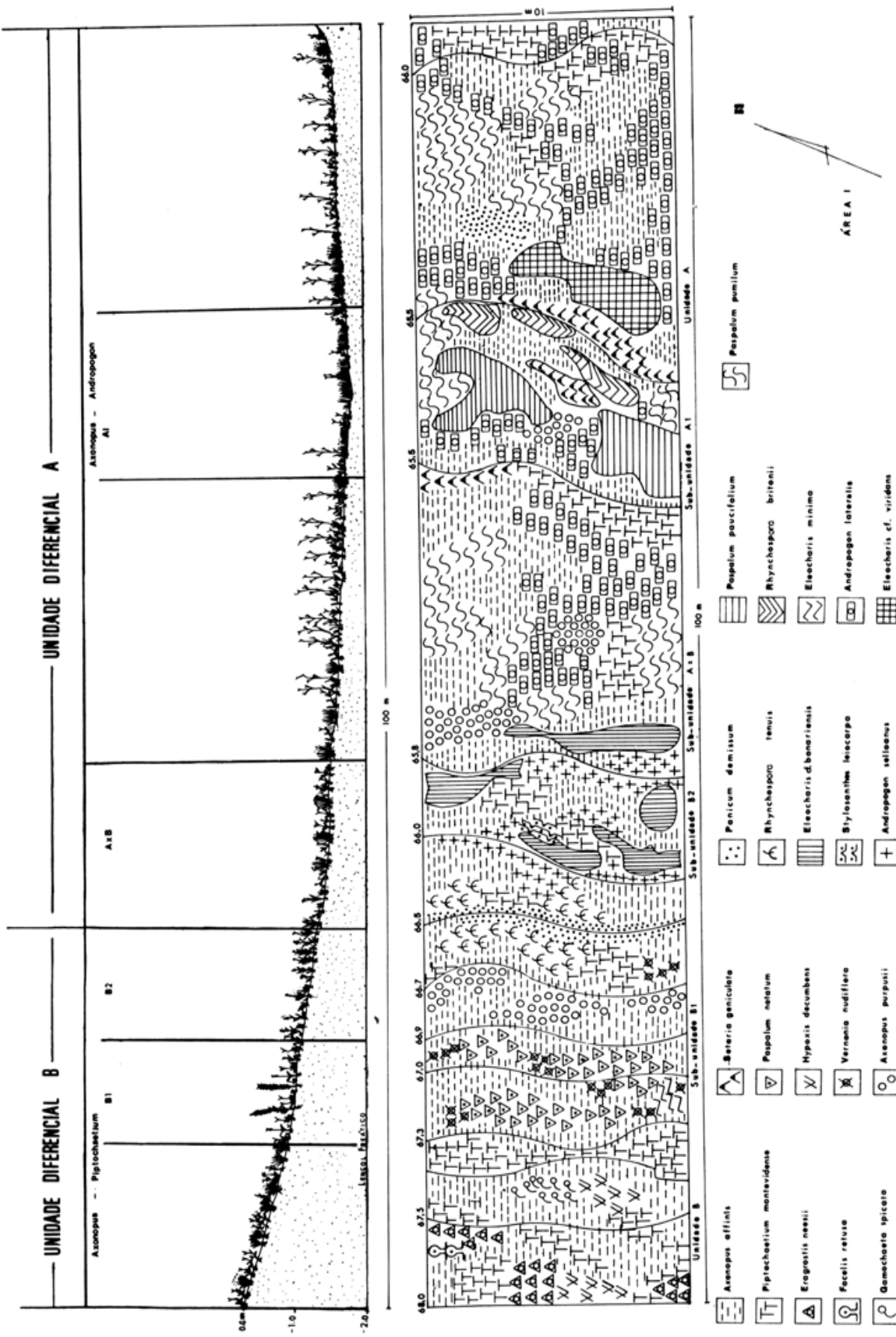

幽

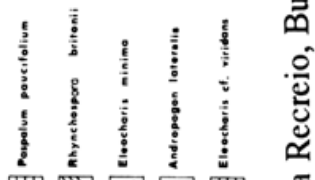

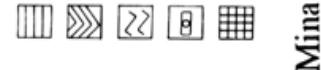

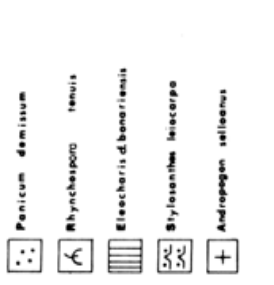

$\cong$

졸

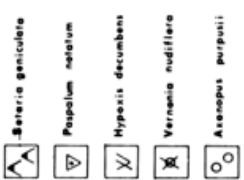

ก

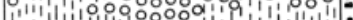

更

年

列

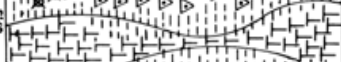

111, II II

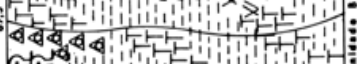

1

: I,

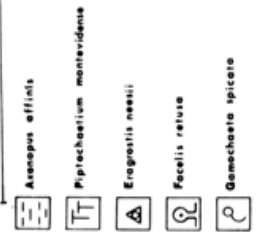

趂

荧 
transição entre o campo com solo seco e campo com solo úmido.

As unidades amostrais pertencentes à unidade diferencial $\mathrm{B}$ e suas respectivas subunidades e subgrupos localizaram-se na parte da área com altitude mais elevada. As espécies que compõem esta unidade, embora penetrem na porção da área com solo mais úmido, apresentam maior abundância e cobertura nas unidades amostrais localizadas na extremidade mais seca da área de campo natural.

Algumas unidades amostrais na área de campo natural delinearam-se exatamente sobre a área de transição entre o campo com solo úmido e o campo com solo seco. Algumas espécies apresentaram ampla distribuição na área amostral, não mostrando claramente a que unidade diferencial pertenciam, evidenciando abundância e cobertura mais significativa nas unidades amostrais da faixa de transição.

Na Tabela 4, os blocos pontilhados representam os grupos de espécies que ocorreram com maior abundância e cobertura sobre esta faixa de transição. As partes pontilhadas dos blocos sólidos representam a interpenetração das espécies nesta faixa intermediária.

Verificou-se, portanto, que uma subunidade se delineou nesta faixa intermediária, a subunidade A x B, composta pelas espécies Herbertia pulchella, Mitracarpus megapotamicus, Plantago myosuros, Andropogon selloanus, Pfaffia tuberosa, Eleocharis cf. bonariensis, Stylosanthes leiocarpa, Habenaria sp. e Mecardonia tenella.

Mueller-Dombois \& Ellenberg (1974) sugeriram que as unidades amostrais que apresentem falta de certas espécies, ou que contenham certo número de espécies que não ocorram em outras, devem ser extraídas da análise fitossociológica, pois não fazem parte das comunidades que tendem a delinear-se na tabela reestruturada. Portanto, de acordo com esses autores, as unidades amostrais que se localizaram sobre a faixa de transição deveriam ser retiradas desta análise. Como a amostragem foi aleatória e não preferêncial, e o objetivo do trabalho não é, em última instância, classificar a vegetação dentro das categorias propostas por alguns autores, entre os quais Braun-Blanquet, mas sim verificar a composição básica da área de campo natural e a variação existente entre as subunidades de vegetação a fim de compará-la com a vegetação das áreas mineradas, as quais apresentam composição florística em diferentes estágios de desenvolvimento, optou-se por incluir estas unidades amostrais na análise fitossociológica.

Entre as espécies que ocorreram na amostragem fitossociológica (Tabela 2), três destacaram-se pela amplitude de distribuição na área de campo natural: Axonopus affinis, Centella hirtella e Sizyrinchium sp dentre as quais, A. affinis evidenciou maior abundância e cobertura, sendo por isto escolhida juntamente com a espécie de maior abundância e cobertura dentro de cada unidade (Tabela 4) para denominá-la. Assim, denominou-se a unidade diferencial A de Axonopus Andropogon, e a unidade diferencial B de Axonopus - Piptochaetium, a subunidade B1 de Axonopus - Piptochaetium - Paspalum e a subunidade B2 de Axonopus Fiptochaetium - Panicum.

As denominações de "unidades, subunidades e subgrupos de gevetação", 
referindo-se aos grupos de espécies formados, também foram simples denominações para diferenciar os grupos de espécies que ocorreram em maior ou menor número de unidades amostrais, não se tendo a preocupação de enquadrar estes dentro da nomenclatura para comunidades proposta por Braun-Blanquet (1950). Para tanto, seria necessário que estudos mais intensos fossem realizados nesta área, bem como na região fisiográfica a que a mesma pertence, a fim de obter-se conhecimento maior das comunidades campestres para que fosse possível relacionar os tipos de comunidades que ocorrem nesta região com aqueles que possivelmente se delinearam na área estudada.

A análise de concentração aplicada à tabela estruturada 4, gerou quatro variáveis canônicas, sendo que as duas primeiras explicaram $87,3 \%$ da variação total da informação. Gerou ainda escores canônicos para os grupos de unidades amostrais e de espécies, os quais serviram como coordenadas para a localização destes grupos no diagrama de dispersão (Figura 4). Neste diagrama, os grupos de espécies estão representados pela letra $\mathrm{S}$, e os de amostras pela letra $\mathrm{F}$. Na análise deste diagrama, consideraram-se apenas as duas primeiras variáveis canônicas, sendo que a disposição dos grupos de espécies e unidades amostrais tende a refletir a mesma configuração obtida na Tabela 4 . Supõe-se que o fator umidade seja o principal determinante da distribuição das espécies, considerando-se a mesma como a variável canônica $1 \mathrm{e}$ a declividade do terreno como a variável canônica 2 .

A proximidade entre os grupos de unidades amostrais na figura 4 reflete a similaridade florística que há entre os mesmos, e a proximidade destes com os grupos de espécies permite identificar qual ou quais grupos de espécies estão caracterizando cada grupo de unidades amostrais. Os grupos circulados com linha cheia evidenciam os grupos de espécies e de unidades amostrais que se delinearam no campo de baixada e na parte da área com altitude mais elevada; e os circulados com linha pontilhada representam os grupos que ocorreram sobre a faixa de transição.

Na área II registraram-se 14 famílias, 39 gêneros e 52 espécies. Destacaramse, pelo número de gêneros e espécies, as mesmas famílias da área de campo natural, Gramineae ( 9 gêneros e 19 espécies), Compositae (10 gêneros e 13 espécies) e Cyperaceae ( 3 gêneros e 5 espécies).

Submeteram-se os dados obtidos na amostragem fitossociológica das 26 unidades amostrais desta área (Tabela 5) à mesma rotina de análise a que se submeteu,a área de campo natural. O objetivo de analisar fitossociológicamente esta área, bem como a área III, que será tratada a seguir, foi obter uma tabela estruturada da vegetação em cada área, a fim de compará-las entre si e com a da área de campo natural, verificando-se assim se as unidades de vegetação que estão delineando-se nestas áreas são as mesmas ou estão tendendo para as que ocorreram na área de campo natural.

Dentre as 52 espécies registradas no levantamento fitossociológico, selecionaram-se 19 com freqüência entre 60 e $10 \%$ (ocorrendo entre 3 e 15 vezes em 25 unidades amostrais). 


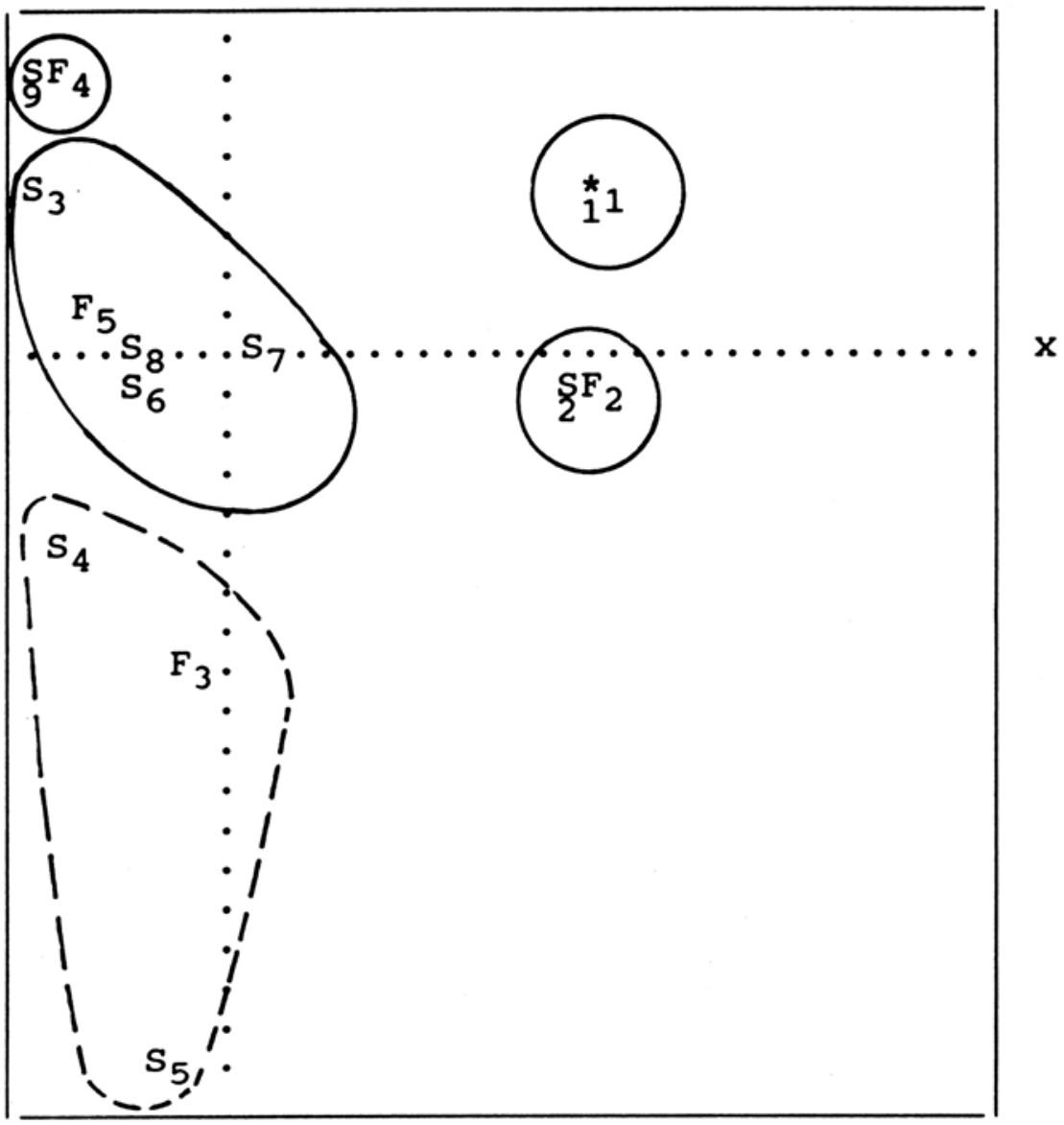

Figura 4 - Diagrama de dispersão dos grupos de unidades amostrais (F) e grupos de espécies (S) da tabela 4, em função das variáveis canônicas 1 e 2 . Os grupos circulados por linha pontilhada, ocorreram na área de transição entre o campo com solo úmido e com solo bem drenado, na área de campo natural, Mina Recreio, Butiá - RS.

* - Indica a sobreposição dos grupos de espécies 2 e unidades amostrais 2

- O eixo $x$ representa a variável canônica 1 (umidade) e o eixo y a variável canônica 2 (declividade).

Com base na abundância e cobertura destas espécies, obteve-se a classificação das unidades amostrais. Reduziu-se o número de unidades amostrais de 26 para 25 , pois a 26 a apresentou espécies que ocorreram apenas uma ou duas vezes na amostragem total da área, sendo eliminadas da análise propriamente dita. 
Conforme a tabela estruturada 6 , o estágio de desenvolvimento da vegetação na área II no momento do estudo evidencia que há forte tendência à formação de uma unidade diferencial principal, composta pelas espécies Cynodon dactylon, Panicum sabulorum, Axonopus affinis e A. purpusii. Denominou-se esta unidade diferencial de A.

Verifica-se ainda que possivelmente duas subunidades A1 e A2 estariam começando a se delinear. A subunidade A1, composta pelas espécies Evolvulus sericeus, Paspalum plicatulum, P. dilatatum, Acanthospermum australe, Rhynchospora tenuis, Dichondra seriacea, Eragrostis lugens e Rhynchospora rugosa, distribui-se por toda a área amostral, formando pequenas manchas em alguns locais; e a subunidade A2 restringe-se a uma pequena parte da área amostral, configurando também pequenas manchas; formada pelas espécies Desmanthus virgatus, Aspilia montevidensis, Eragrostis polytricha, Senecio cisplatinus, Baccharis dracunculifolia, Mitracarpus megapotamicus e Panicum demissum.

Tabela 5 - Abundância e cobertura das 52 espécies registradas nas 26 unidades amostrais na área II, Mina Recreio, Butiá - RS, estimada pela escala de abundância e cobertura de Braun-Blanquet (1950).

\begin{tabular}{|c|c|c|c|c|c|c|c|c|c|c|c|c|c|c|}
\hline 1 & Cynodon dactylon & 2 & & & 1 & & 31 & 2 & & & 1 & 1 & & \\
\hline 2 & Acanthospermum australe & 1 & + & + & + & + & R 1 & & 1 & $1+$ & $\mathrm{R}+$ & & + & \\
\hline 3 & Panicum demissum & 1 & 1 & 1 & $1+2$ & 1 & + & + & & + & & 2 & & + \\
\hline 4 & Paspalum dilatatum & + & + & & & + & R R & 1 & & $\mathrm{R}$ & 12 & & & \\
\hline 5 & Senecio brasiliensis & $\mathrm{R}$ & & & & & & & & & & & & + \\
\hline 6 & Desmodium incanum & 2 & & & & & & & & & & & & 1 \\
\hline 7 & Aspilia montevidensis & 2 & & & & & & + & & & & 11 & & + \\
\hline 8 & Panicum sabulorum & 1 & +1 & 1 & & 1 & & 1 & 1 & & 22 & & 1 & 2 \\
\hline 9 & Piptochaetium montevidense & 2 & 222 & 32 & 223 & 21 & & & +2 & 132 & 232 & $2+2$ & 22 & 2 \\
\hline 10 & Axonopus purpusii & 1 & 22 & & 1 & 2 & & & 22 & +1 & 21 & 11 & $\mathrm{R}$ & \\
\hline 11 & Tibouchina $g$ & $\mathrm{R}$ & & & & & & & & & & & & \\
\hline 12 & Baccharis dracunculifolia & $\mathrm{R}$ & & & $+\mathrm{R}$ & 2 & & & & & & +35 & 52 & 1 \\
\hline 13 & Desmanthus virgatus & 1 & & & & & & & & $\mathrm{R}$ & & & & 1 \\
\hline 14 & Paspalum plicatulum & 1 & $+\mathrm{R} 1$ & $1+$ & + & 1 & & & & + & & $22+$ & +1 & + \\
\hline 15 & Setaria geniculata & $\mathrm{R}$ & +2 & 11 & 111 & $1+$ & 1 & + & + & +1 & & 11 & 2 & 1 \\
\hline 16 & Axonopus affinis & & 2 & $\mathrm{R}$ & + & R 2 & + & & 1 & +12 & 222 & & 1 & , \\
\hline 17 & Mitracarpus megapotamicus & & $\mathrm{R}$ & & R R & $\mathrm{R}$ & & & & & & & & \\
\hline 18 & Baccharis articulata & & 2 & & & & & & & & & & & + \\
\hline 19 & Turnera sidoides & & + & & & & & & & & & & + & \\
\hline 20 & Gamochaeta cf. spicata & & $\mathrm{R}$ & & & & & & & & & & & \\
\hline 21 & Mecardonia tenella & & $\mathrm{R}$ & & & & & & & & & & & \\
\hline 22 & Aristida jubata & & $R$ & $\mathrm{R}$ & & & & & & & & & & \\
\hline 23 & Dichondra sericea & & 1 & & & 1 & & & & & & & & + \\
\hline 24 & Hybanthus parviflorus & & + & & & & & & & & & & & \\
\hline
\end{tabular}


Cont. Tabela 5

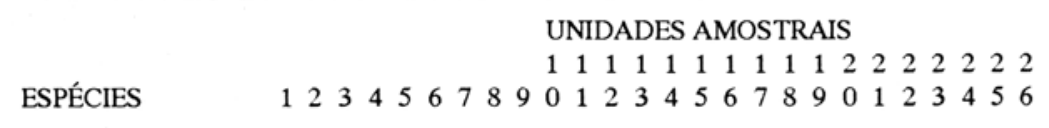

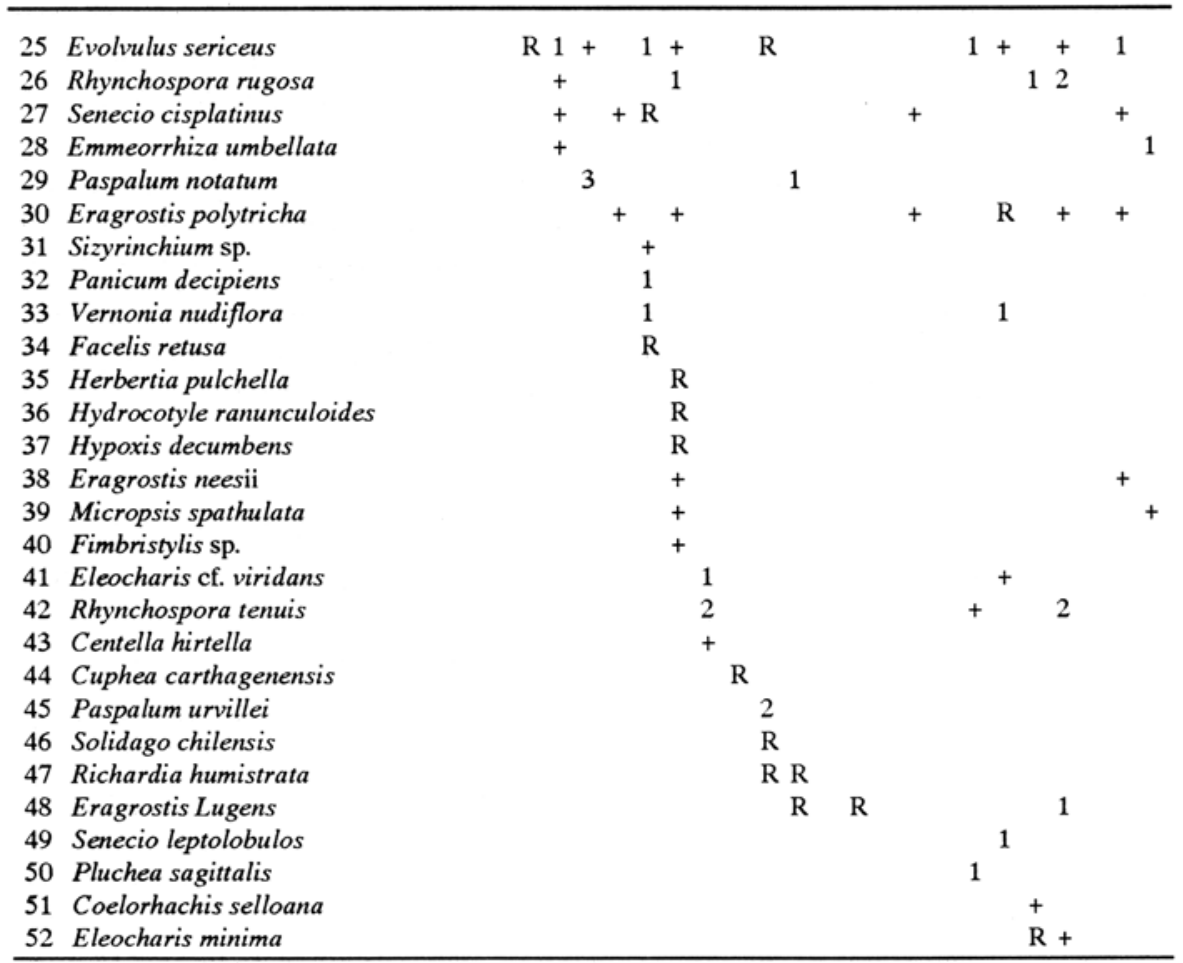

Na verdade, nesta área a unidade de vegetação A, bem como suas subunidades, não se delinearam muito claramente. É certo que há evidências, pela configuração da tabela estruturada 6 , da formação de grupos de espécies que tendem a ocorrer juntas; no entanto, o estágio de desenvolvimento da vegetação, no momento do estudo, não permitiu separação muito clara das unidades amostrais, nem dos grupos de espécies que tendem a ocorrer juntas.

Observa-se ainda que há uma interpenetração, ou ampla distribuição das espécies na área amostral, onde tendem a se estabelecer em pequenos aglomerados, apresentando espaços totalmente desprovidos de vegetação. Este fato se deve em particular às más condições geradas pelas atividades de mineração, impedindo assim que a vegetação se expanda e ocupe por inteiro os espaços disponíveis. 
Tabela 6 - Abundância e cobertura das 19 espécies mais importantes da área II, Mina Recreio, Butiá - RS, ordenadas juntamente com as unidades amostrais, pelos grupos gerados na análise de agregação.

GRUPOS DE UNIDADES AMOSTRAIS

1122222222223334444444445555566

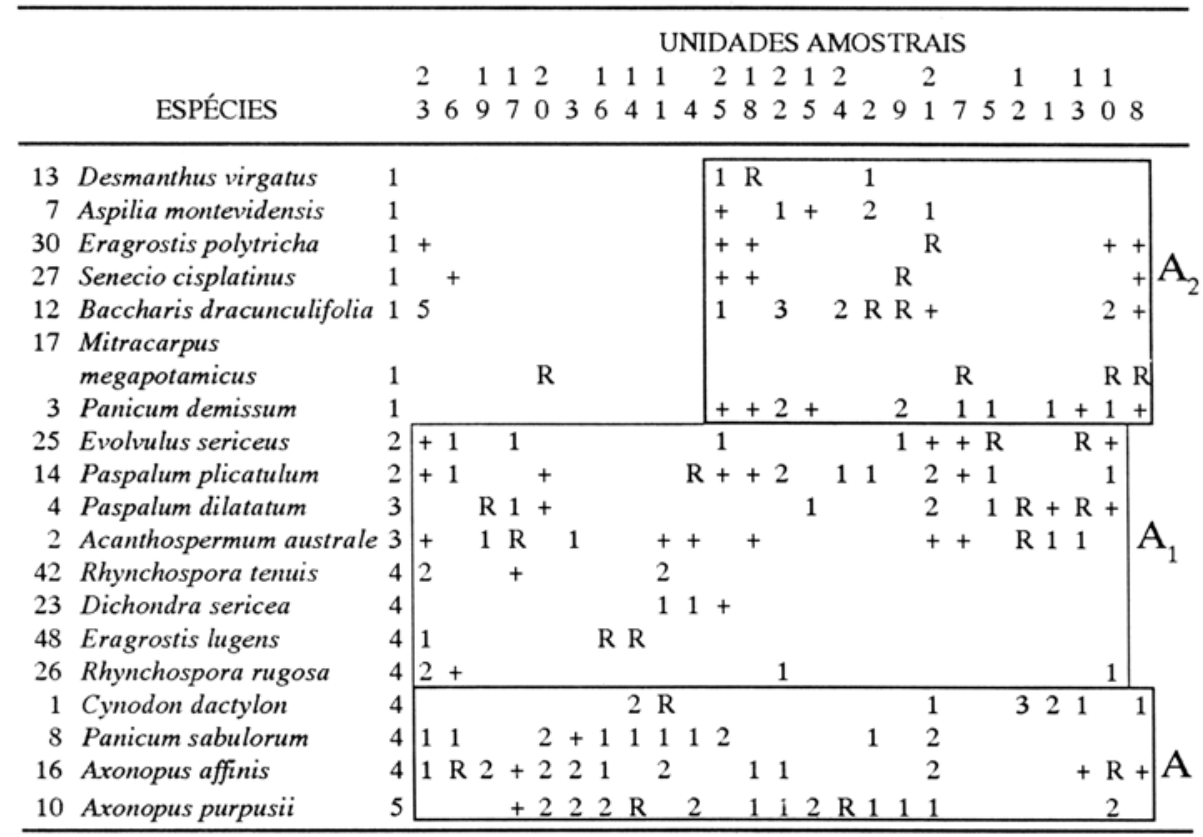

A amostragem, sendo aleatória e não preferencial nas áreas mineradas onde a vegetação não ocupou todos os espaços, gerou na tabela estruturada uma descontinuidade da vegetação, não pela ausência de algumas espécies em detrimento de outras, mas sim pela ausência de plantas em partes das unidades amostrais, chegando-se a registrar até $90 \%$ de ausência de cobertura vegetal, evidenciando o caráter da vegetação em forma de manchas. Analisando-se o mapa e perfil da vegetação (Figura 5), verifica-se melhor o que foi acima exposto. Nas áreas mineradas, a ausência de espécies em algumas partes dá-se devido à tênue espessura da camada de argila e de solo vegetal que é colocada sobre os rejeitos piritosos. Na recomposição de áreas que recebem reencapamento com o próprio solo vegetal retirado dos cortes antes da mineração, recomenda-se para o cultivo de gramíneas que esses solos sejam de uma espessura mínima de 5 a $8 \mathrm{~cm}$; para o plantio de árvores e arbustos, deve ser superior a $30 \mathrm{~cm}$ (Canadá, 1975 apud Griffith, 1980). A ação erosiva da chuva e do vento desgastam esta camada, expondo os estéreis e os rejeitos piritosos utilizados para preencher a lavra. Poucas espécies conseguem 


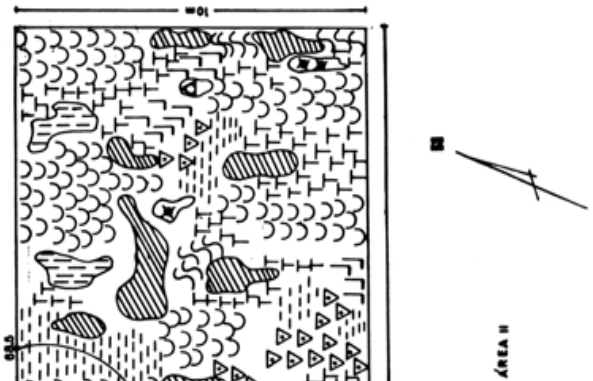

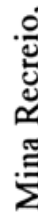
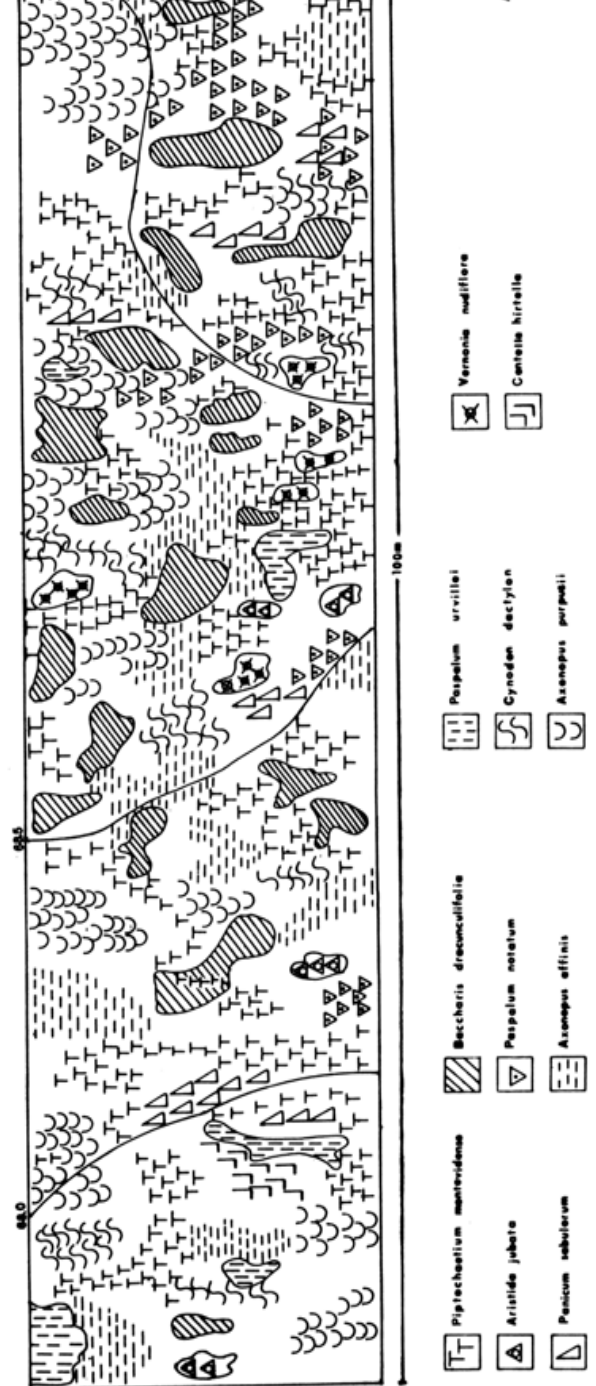

ळ్

올

ะี

놀

\%

ญ्.

0

꾺

冚

芯

ํํㅇ

뜰

얿

త్ర్త

짐

恶

(

粱

荧 
se estabelecer nestes locais inóspitos, havendo maior concentração onde a inclinção do terreno não é muito acentuada e a camada de solo mais espessa. $\mathrm{Na}$ Califórnia, Tyson (1979) verificou que $5 \mathrm{~cm}$ de solo misturado com cobertura morta foi suficiente para o estabelecimento de gramíneas e arbustos.

Duas espécies na área II destacaram-se com constância acima de $60 \%$, Piptochaetium montevidense, ocorrendo 21 vezes em 26 unidades amostrais, e Setaria geniculata, 17 vezes. Escolheu-se $P$. montevidense, juntamente com a espécie de maior abundância e cobertura da unidade diferencial A, para denominar a comunidade campestre da área II de Piptochaetium - Axonopus purpusii.

Submeteram-se os resultados da tabela estruturada 6 à análise de concentração, onde se geraram 4 variáveis canônicas, sendo que as duas primeira explicam $72,20 \%$ da variação total da informação. Obtiveram-se ainda escores canônicos para os grupos de unidades amostrais e de espécies, conforme mostra o diagrama (Figura 6).

$\mathrm{Na}$ área III encontraram-se 14 famílias, 28 gêneros e 38 espécies, dentre as quais destacaram-se duas famílias: Gramineae (9 gêneros e 16 espécies) e Compositae (6 gêneros e 8 espécies).

Novamente, submeteram-se os dados fitossociológicos à seqüência de análise anterior empregada nas áreas de campo natural e área II. Das 38 espécies ocorrentes (Tabela 7), selecionaram-se apenas 13 com freqüência entre 60 e $10 \%$.

Nesta área, em grande parte desprovida de vegetação no momento do estudo, também se amostraram 26 unidades, das quais 6 localizaram-se sobre partes totalmente descobertas, sendo consideradas na análise fitossociológica apenas 20. Igualmente, mantiveram-se os limites de constância de 60 e 10\%, utilizando-se, na análise fitossociológica, apenas as espécies que apareceram entre 2 e 12 vezes em 20 unidades amostrais. Submeteram-se as unidades amostrais à classificação segundo o critério de similaridade florística e as $\mathbf{1 3}$ espécies selecionadas, segundo distribuição na área amostral, conforme executado nas duas áreas anteriores.

Com base nestas informações obteve-se a tabela estruturada 8 , na qual se verifica que a configuração da distribuição das manchas de vegetação da área II tende a repetir-se nesta, apresentando uma possível unidade diferencial A, formada pelas espécies Paspalum urvillei, Axonopus affinis e Cynodon dactylon, que se distribuem em quase toda a área amostral. Novamente as manchas de vegetação evidenciam a descontinuidade observada em campo. Esta descontinuidade caracteriza-se pela ausência total da vegetação e não pela ausência de algumas espécies em detrimento de outras como foi mencionado para a área II (Figura 7).

Juntamente com a unidade diferencial A, formaram-se quatro subunidades: A1, A2, A3 e A4. A subunidade A1, composta por Mimosa bimucronata e Cyperus laetus, ocorreu preferencialmente nas partes mais baixas, onde na época de chuvas o lençol freático aflora. Observa-se ainda que, embora esta subunidade, assim como as demais, não se tenham delineado claramente, as espécies tendem a ocorrer juntas formando manchas. 


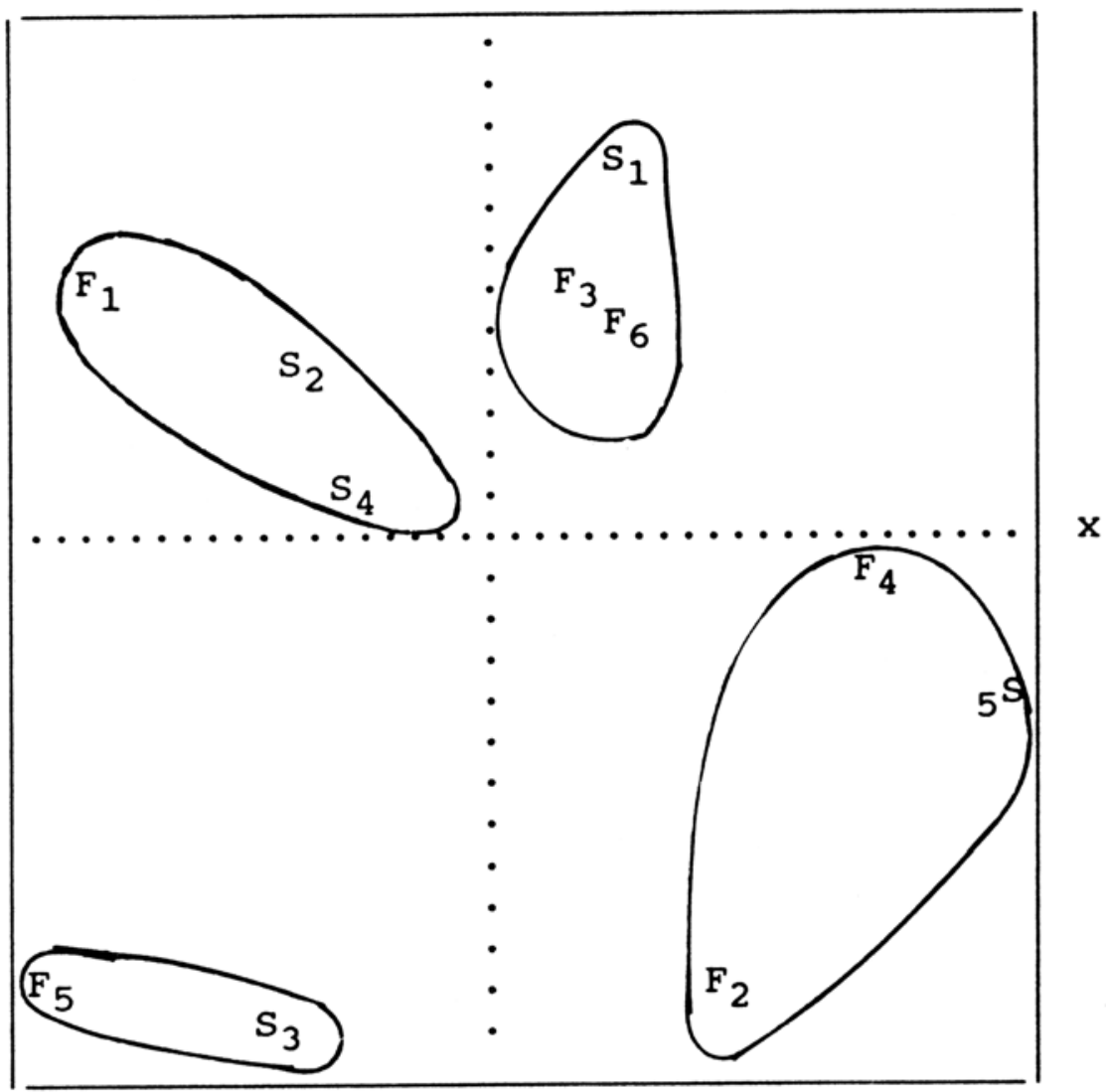

Figura 6 - Diagrama de dispersão dos grupos de unidades amostrais (F) e grupos de espécies (S) da tabela 6, em função das variáveis canônicas 1 e 2.

- O eixo x representa a variável canônica 1 e o eixo y a variável canônica 2 .

A subunidade A2 está composta por Pfaffia tuberosa e Paspalum dilatatum, a subunidade A3 compõe-se por Richardia humistrata, Bryum $\mathrm{sp}$, Setaria geniculata, Panicum demissum e Axonopus purpusii, e a subunidade A4 está composta apenas por Panicum sabulorum, a qual se distribui em toda a área amostral.

Dentre as 38 espécies ocorrentes na amostragem fitossociológica desta área, Piptochaetium montevidense apresentou $100 \%$ de freqüência. Escolheu-se esta espécie, assim como na área II, para denominar a comunidade campestre da área III, juntamente com Cynodon dactylon, que teve maior abundância e cobertura dentro da unidade diferencial que possivelmente se estaria delineando no momento do estudo, sendo denominada de Piptochaetium - Cynodon. 
Tabela 7 - Abundância e cobertura das 38 espécies registradas nas 26 unidades amostrais na área III, Mina Recreio, Butiá - RS, estimada pela escala de abundância e cobertura de Braun-Blanquet (1950).

UNIDADES AMOSTRAIS

$\begin{array}{lllllllllllllllll}1 & 1 & 1 & 1 & 1 & 1 & 1 & 1 & 1 & 1 & 2 & 2 & 2 & 2 & 2 & 2 & 2\end{array}$

ESPÉCIES

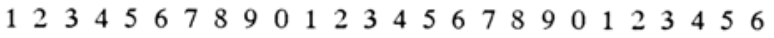

\begin{tabular}{|c|c|c|c|c|c|c|c|c|c|c|}
\hline 1 & Chevreulia sarmentosa & 1 & & & & & & & & \\
\hline 2 & Paspalum dilatatum & 1 & & & & + & + & + & & + \\
\hline 3 & Cynodon dactylon & 1 & 2 & & 15 & R 5 & 515 & 2 & & + \\
\hline 4 & Cyperus laetus & + & & & & 5 & 1 & & & \\
\hline 5 & Axonopus purpusii & + & 1 & & $1+$ & 21 & $11 \mathrm{R}$ & & & + \\
\hline 6 & Cyperus sp. & + & & & & & & 1 & & \\
\hline 7 & Mimosa bimucronata & 5 & & 5 & & + & 1 & 5 & & \\
\hline 8 & Axonopus affinis & & 1 & & 1 & 1 & 3 & 1 & 3 & \\
\hline 9 & Briza minor & & 1 & & & & & & & \\
\hline 10 & Paspalum urvillei & & 1 & $\mathrm{R}$ & + & + & 1 & + & & \\
\hline 11 & Piptochaetium montevidense & & 1 & $1+\mathrm{R} 1$ & 21 & +1 & $1 \mathrm{R}$ & & 2 & 12 \\
\hline 12 & Panicum sabulorum & & 1 & $+\mathrm{R}$ & & & + & & $12+$ & R 2 \\
\hline 13 & Paspalum plicatulum & & 1 & & + & & & & & \\
\hline 14 & Centella hirtella & & & 1 & & & + & & & \\
\hline 15 & Aristida jubata & & & 2 & & & & & & \\
\hline 16 & Baccharis dracunculifolia & & & & + & & & & & \\
\hline 17 & Sizyrinchium sp. & & & & + & & & & & \\
\hline 18 & Panicum demissum & & & & 1 & +1 & & & & \\
\hline 19 & Mitracarpus cf. & & & & & & & & & \\
\hline & megapotamicus & & & & $\mathrm{R}$ & & & & & \\
\hline 20 & Pluchea cf. sagittalis & & & & + & & & & & \\
\hline 21 & Setaria geniculata & & & & $\mathrm{R}$ & & 2 & & & + \\
\hline 22 & Senecio leptolobulos & & & & + & & & & & \\
\hline 23 & Bryum sp. & & & & 1 & 11 & + & & & 1 \\
\hline 24 & Senecio cisplatinus & & & & $\mathrm{R}$ & & & & & \\
\hline 25 & Richardia humistrata & & & & + & & + & & & 1 \\
\hline 26 & Hypoxis decumbens & & & & $\mathrm{R}$ & & & & & \\
\hline 27 & Paspalum notatum & & & & & 1 & & 3 & & \\
\hline 28 & Juncus capillaceus & & & & & 1 & t & & & \\
\hline 29 & Hybanthus parviflorus & & & & & 1 & 1 & & & \\
\hline 30 & Gamochaeta cf. spicata & & & & & + & $+\mathrm{R}$ & & & \\
\hline 31 & Senecio brasiliensis & & & & & $\mathrm{R}$ & $R$ & & & \\
\hline 32 & Cuphea carthagenensis & & & & & $\mathrm{R}$ & R & & & \\
\hline 33 & Gratiola peruviana & & & & & & + & & & \\
\hline 34 & Pfaffia tuberosa & & & & & & & $\mathrm{R}$ & $\mathrm{R}$ & + \\
\hline 35 & Vernonia cf. nudiflora & & & & & & & + & 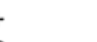 & \\
\hline 36 & Panicum decipiens & & & & & & & $\mathrm{R}$ & 2 & \\
\hline 37 & Eragrostis lugens & & & & & & & & + & \\
\hline 38 & Eragrostis neesii & . & & & & & & & & 1 \\
\hline
\end{tabular}


Aplicou-se aos resultados da tabela estruturada 8 a análise de concentração, onde se extrairam 3 variáveis canônicas, sendo que as duas primeiras explicam $86,40 \%$ da variação total da informação. No diagrama (Figura 8 ) verifica-se que a configuração dos pontos tende a refletir a distribuição dos grupos de espécies e de unidades amostrais, conforme ocorrem na tabela estruturada 8 .

Aplicando-se o índice de similaridade proposto por SØrensen (1928) (apud Mueller-Dombois \& Ellenberg, 1974), obteve-se similaridade entre a área de campo natural e a área II de 51,9\%, e entre a área de campo natural e a área III de $40,35 \%$. Comparando-se as duas áreas mineradas, verificou-se similaridade de $64,4 \%$.

Mueller-Dombois \& Ellenberg (1974) afirmam que a similaridade entre duas comunidades não é função apenas do número de espécies comuns e exclusivas, mas também da quantidade de cada espécie presente. Dependendo do objetivo da pesquisa, diversos critérios podem ser incluídos nos cálculos de similaridade.

Ellenberg (1956) (apud Mueller-Dombois \& Ellenberg, 1974), inclui a percentagem de biomassa (M) de cada espécie no coeficiente de similaridade da Jaccard (1928) (apud Mueller-Dombois \& Ellenberg, 1974), modificando-o. Outros valores podem ser igualmente tratados, por exemplo, um "coeficiente de similaridade baseado na freqüência das espécies" pode ser calculado da mesma forma, utilizando-se a frequiência ao invés dos valores percentuais de biomassa de cada espécie (Mueller-Dombois \& Ellenberg, 1974).

Converteram-se os dados de abundincia e cobertura das espécies ocorrentes na amostragem fitossociológica de cadiı area em percentual de cobertura, conforme sugestões de Mueller-Dombois \& Ellenberg (1974).

Baseando-se na percentagem média de cobertura das espécies de cada área, obteve-se índice de similaridade de $27,55 \%$ entre a área de campo natural e a área II, e $20,35 \%$ entre a área de campo natural e a área III; comparando-se a área II com a área III verificou-se similaridade de $27,75 \%$. Estes índices, embora com menor percentual de similaridade entre as áreas analisadas, apresentam a mesma tendência que os resultados obtidos por meio do índice de similaridade de SØrensen (1928) (apud Mueller-Dombois \& Ellenberg, 1974).

De acordo com os resultados obtidos pelos dois índices de similaridade, verifica-se que de certa forma a topografia influencia no estabelecimento e desenvolvimento da vegetação. A área II localiza-se em uma elevação suave, enquanto que a área III localiza-se em uma baixada apresentando certa declividade, favorecendo a atividade erosiva da chuva. Tal fato contribui para o desgaste da camada de solo vegetal, lixiviando os nutrientes, além de favorecer a locomoção dos metais pesados que estão aderidos às partículas do solo.

Nas áreas mineradas (II e III), devido aos grupos de espécies não se terem delineado muito claramente, preferiu-se não nomear quais seriam as variáveis ambientais que teriam maior peso para condicionar a distribuição da vegetação no momento do estudo. Supõe-se que a concentração de metais pesados no solo, a deficiência de nutrientes, baixa capacidade de retenção de água e uma série de 

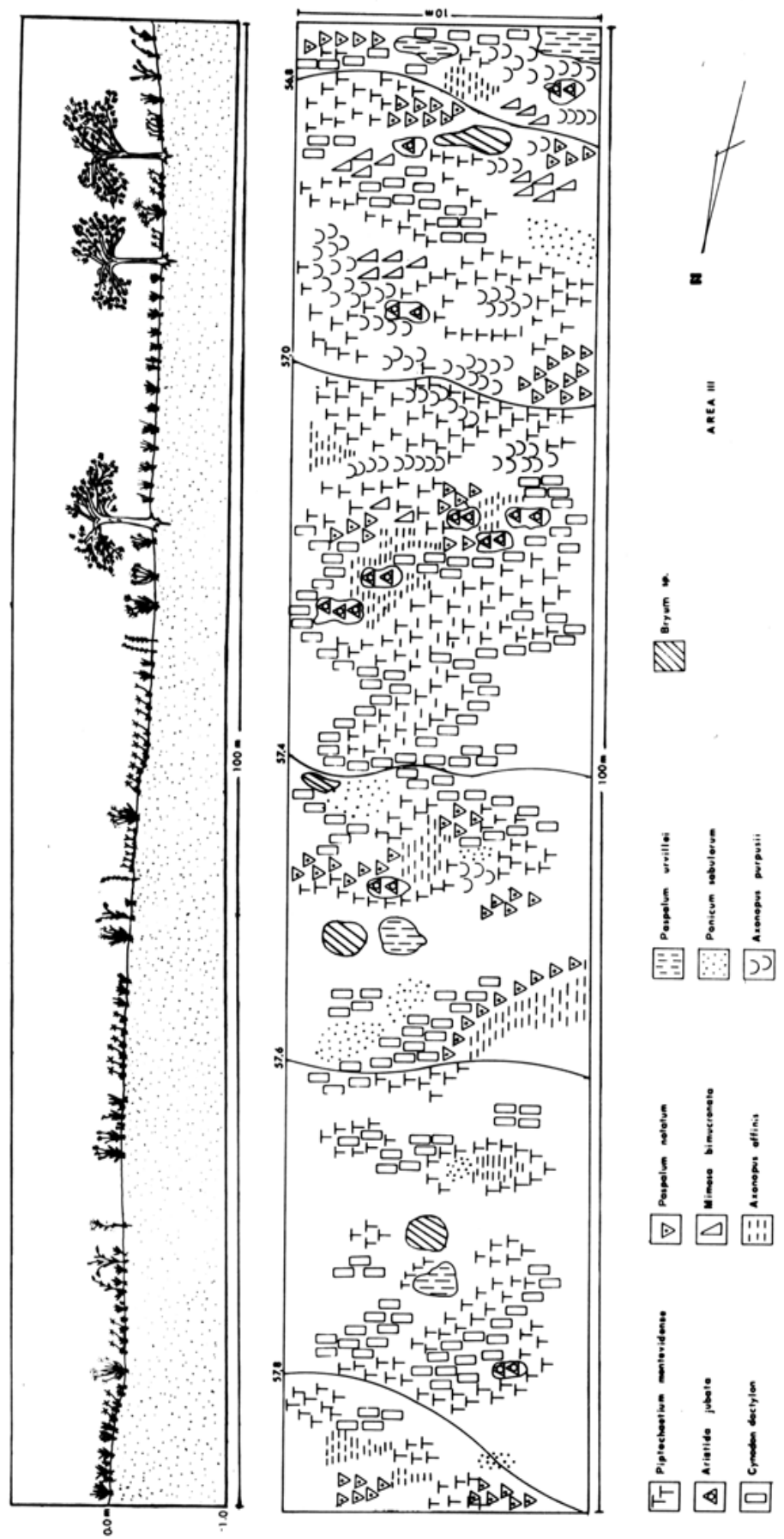

얼

$\stackrel{\text { I }}{\Sigma}$

ஓ

(2)

ธิ

임

\&

\&

壱

꼬ำ

త్

0

꼰

@

巳్

응

똥

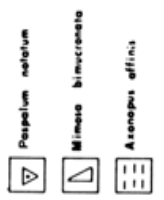

เำ

トト占上 号号

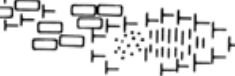
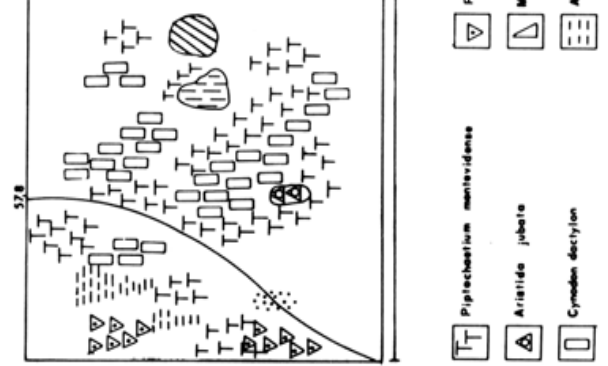

焉

o

荧

$\therefore \dot{2}$

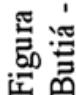


fatores microclimáticos a que as áreas mineradas estão submetidas, estejam atuando conjuntamente. No entanto, com base nos resultados obtidos neste trabalho, não é possível afirmar quais fatores tem maior significado no estabelecimento e desenvolvimento da vegetação nas áreas pós-mineradas.

Ruffner \& Steiner (1973) alegam que, diante da multitude de fatores que condicionam o estabelecimento e desenvolvimento da vegetação nas áreas de rejeitos de carvão e em função das variações nas condições ambientais, torna-se impossível identificá-los. Combinações de toxidez, $\mathrm{pH}$ e declividade são agravadas por fatores climáticos como umidade, temperaturas extremas e exposição.

Bauer (1973) sugere que a granulometria do substrato e níveis baixos de matéria orgânica em presença de grandes quantidades de cascalho e areia, assim como níveis altos de matéria orgânica e ácidos húmicos em presença de rejeitos de carvão, bem como a erosão, acidez do solo, deficiência hídrica e condições microclimáticas extremas, são os principais fatores abióticos determinantes do estabelecimento da vegetação nas áreas pós-mineradas.

Berg \& Vogel (1973) atribuem a dificuldade no estabelecimento da cobertura vegetal à toxidez dos rejeitos extremamente ácidos causada pelo excesso de $\mathrm{Mn}$ solúvel e outros metais, mais provavelmente o $\mathrm{Al}$.

Tabela 8 - Abundância e Cobertura das 13 espécies mais importantes da área III, Mina Recreio, Butiá - RS, ordenadas juntamente com as unidades amostrais, pelos grupos gerados na análise de agregação.

GRUPOS DE UNIDADES AMOSTRAIS

$\begin{array}{lllllllllllllllllll}1 & 1 & 2 & 2 & 2 & 2 & 3 & 3 & 4 & 4 & 4 & 4 & 4 & 4 & 4 & 4 & 4 & 4 & 4\end{array}$

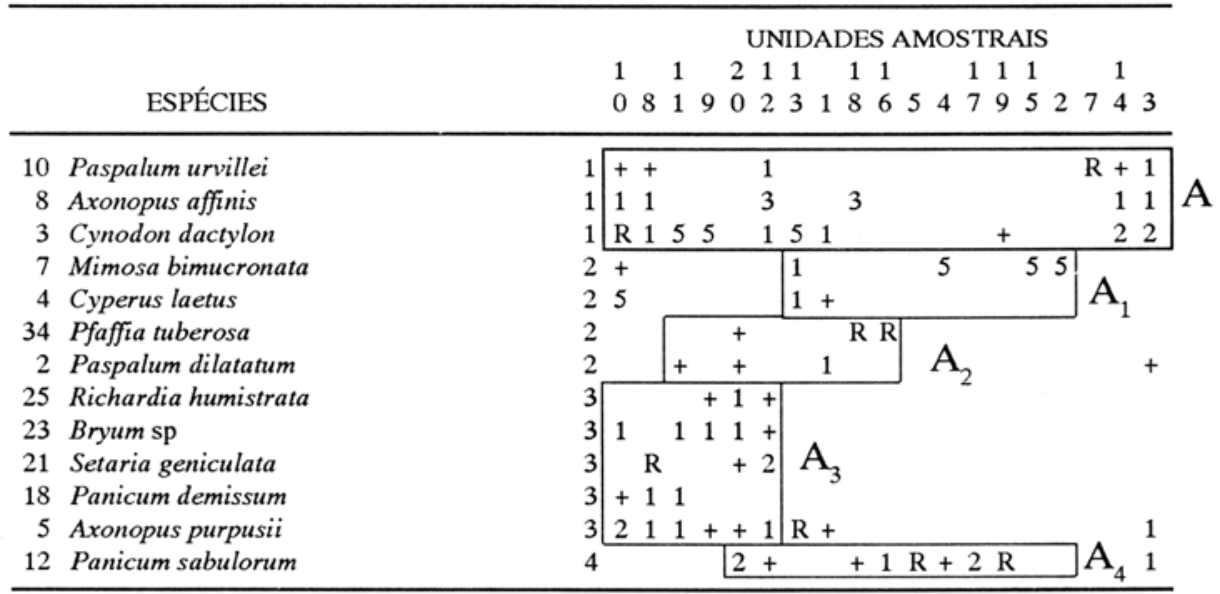


$\mathrm{Na}$ parte II do presente estudo inclui-se análise dos metais pesados no substrato e nas plantas, provenientes do rejeito do carvão. Evidenciou-se concentrações elevadas de cobalto, cromo, níquel e ferro, que levam a supor, que os metais pesados, juntamente com outros fatores do solo e topografia, estejam influindo na definição das possíveis associações vegetais das áreas II e III.

Todo desenvolvimento de associações vegetais leva tempo. Bauer (1973), estudando a vegetação de áreas pós-mineradas de carvão, verificou que depois de dez anos da vegetação estar firmemente estabelecida, as associações vegetais ainda não existiam. Afirma ainda que as plantas pioneiras conservam suas áreas e impedem a germinação de espécies recém chegadas, e a associação final das espécies que invadem o local já minerado pode ser diferente da associação original.

Pela análise das tabelas estruturadas 4, 6 e 8 , observa-se que a vegetação das áreas mineradas, por se encontrar nos primeiros estágios de desenvolvimento e por não ter ocupado toda a extensão da área, apresenta certas espécies como Piptochaetium montevidense e Cynodon dactylon com abundância e cobertura relativamente altas. Tais espécies, quando o ambiente está totalmente tomado pela vegetação, formando um tapete denso, parecem não competir muito bem com, por exemplo, Axonopus affinis e Paspalum notatum, necessitando de muito espaço para se desenvolverem. Verificou-se ainda no presente estudo que Cynodon dactylon e Piptochaetium montevidense apresentam certo grau de pioneirismo em relação a outras espécies, sendo que, com o desenvolvimento da vegetação, estas tendem a ser substituídas por outras.

Quanto a competição entre espécies vegetais nas áreas de rejeitos de mineração de carvão Bauer (1973) postula o seguinte: “Após alguns anos da recolonização, arbustos e árvores começam a crescer e as condições ecológicas mudam lentamente. Espécies que se reproduzem vegetativamente e, portanto, têm mais sucesso na competição, persistem. As chances das espécies invasoras desaparecem por causa do sombreamento, e novas espécies florestais são adicionadas".

Condições ambientais tais como sombreamento e propriedades do solo, são muito mais importantes que a competição como tal, desde que haja espaço suficiente. Bauer (1973) observou que um crescimento rápido segue o estágio pioneiro e que somente após dez anos a competição começou a tomar parte da determinação final das associações vegetais, nas áreas mineradas por ele estudadas.

Cornwell (1971), trabalhando em áreas de mineração de antracito em Illinois, Pensilvânia, USA, concluiu que não se pode descrever uma sucessão vegetal típica, fato já observado por outros autores, referenciados pelo mesmo. Cada área de mineração de carvão apresenta suas particularidades, como a composição química dos rejeitos, exposição destes ao ar e à água, método de extração etc que diferenciam a composição do novo substrato. Portanto, há uma enorme variação nos fatores determinantes da recomposição vegetal, os quais tendem a impedir a ocorrência de uma sucessão vegetal típica à estas áreas

Segundo Bauer (1973) a habilidade para germinar rapidamente e a baixa exigência sobre a qualidade do ambiente são fatores que selecionam os invasores 
com sucesso nas áreas mineradas, em face da multitude de espécies vegetais que atingem estas áreas ou são levadas pelos animais. Afirma ainda, que as espécies que se estabelecem nas áreas mineradas após as pioneiras não as suplantam, mas apenas preenchem nichos livres. Além disso, nestas áreas encontra-se um mosaico de espécies vegetais diferentes e não uma associação propriamente dita. Tais suposições estão de acordo com o que se observou em campo no presente estudo.

Em duas áreas de uma mesma região, verificou-se uma certa diferenciação florística e fitossociológica.

\section{Y}

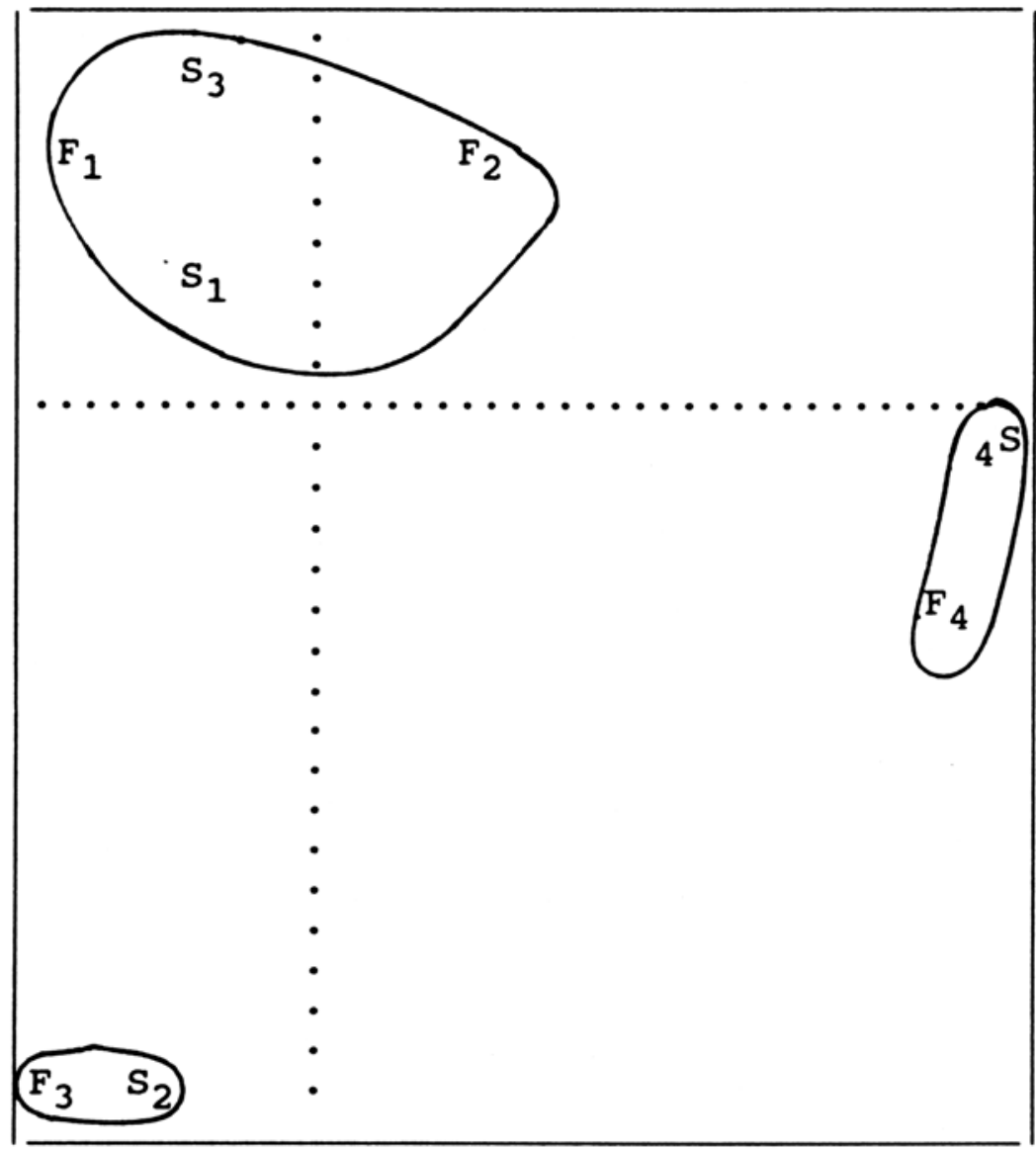

Figura 8 - Diagrama de dispersão dos grupos de unidades amostrais $(F)$ e grupos de espécies (S) da tabela 8 , em função das variáveis canônica 1 e 2 . - O eixo x representa a variável canônica 1 e o eixo y a variável canônica 2 . 
Conclui-se que:

1. Na área de campo natural, há uma variação espacial gradual na vegetação, determinada principalmente pelo conjunto de condições associadas a declividade do terreno e profundidade do lençol freático.

2. Em função desta variação, delinearam-se nesta área duas unidades de vegetação principais: Axonopous - Andropogon, característica do campo de baixada com solo umido e Axonopus - Piptochaetium, característica do campo de encosta com solo bem drenado, ambas com subgrupos de espécies possivelmente associadas.

3. Nas áreas mineradas, embora as unidades de vegetação não se tenham delineado claramente, há evidências de ocorrer uma unidade de vegetação principal do tipo Piptochaetium - Axonopus purpusii na área II e Piptochaetium Cynodon na área III, as quais evidenciam o caráter pioneiro da vegetação das áreas mineradas.

4. Dentre as duas áreas mineradas estudadas, verificou-se maior similaridade florística entre a área II e a área de campo natural do que entre esta e a área III; conclui-se que a área II está apresentando conjunto de condições mais favoráveis à recolonização vegetal do que a área III.

5. A maior similaridade florística verificada entre a área de campo natural e a área II vem confirmar que a declividade do terreno é fator limitante no estabelecimento da vegetação nas áreas pós-mineradas, devendo, portanto, ser atenuada nos trabalhos de recomposição.

6. A configuração da vegetação, em forma de manchas isoladas nas áreas mineradas, reflete o conjunto de condições extremas após a mineração. Evidenciase, portanto, que as espécies presentes apresentam um certo grau de pioneirismo e tolerância em relação a este conjunto de condições extremas, e devem ser as primeiras a serem testadas em trabalhos de recomposição de áreas mineradas.

\section{Agradecimentos}

Agradecemos à Companhia de Pesquisas e Lavras Minerais - COPELMI, ao Conselho Nacional de Desenvolvimento Científico e Tecnológico, CNPq, e a Coordenação de Aperfeiçoamento de Pessoal de Nível Superior, CAPES, pelo financiamento dos estudos; ao Centro de Ecologia e ao Curso de Pós-Graduação em Ecologia da Universidade Federal do Rio Grande do Sul, pela oportunidade de realização do presente trabalho.

\section{Referências Bibliográficas}

BAUER, H.J. 1973. Ten year's studies of biocenological succession in the excavated mines of the Cologne Lignite District. In Hutnik, R.J. \& Davis, G. (eds.). Ecology and reclamation of devastated land. v. 1, p. 271-283. Gordon \& 
Breach, New York.

BERG, W.A. \& W.G. VOGEL. 1973. Toxicity of acid coal-mine spoils to plants. In: Hutnik, R.J. \& Davis, G. (eds.). Ecology and reclamation of devastated land. v. 1., p. 57-67. Gordon \& Breach, New York.

BRAUN-BLANQUET, J. 1950. Fitosociologia; bases para el estudio de las comunidades vegetales, Blume, Madrid.

BOLDRINI, I.I. \& S.T.S. MIOTTO. 1987. Levantamento fitossociológico de um campo limpo da Estação Experimental agronômica, UFRGS, Guaiba, RS. Acta Botânica Brasílica, 1: 49-56.

CANADÁ. Ministery of Natural Resources. 1975. Vegetation for rehabilitation of pits and guarries. Ontario, Division of Forests. 38p. Apud Griffith, J.J. 1980. Recuperação conservacionista de superfícies mineradas; uma revisão de literatura. Sociedade de Investigações Florestais. 51p. (Boletim técnico, 2) Universidade Federal de Viçosa, Viçosa.

CITADINI-ZANETTE, V. 1982. Levantamento florístico da área de recuperação da mineração a céu aberto em Siderópolis, Santa Catarina. Florianópolis, Governo do Estado de Santa Catarina, Gabinete do Planejamento e Coordenação Geral - GAPLAN, Fundação de Amparo a Tecnologia e ao Meio Ambiente - FATMA.

CORNWELL, S.M. 1971. Anthracite mining spoils in Pensylvania; I - Spoils classification and plant cover studies. Journal of Applied Ecology, 8: 401409.

GRIFFITH, J.J. 1980. Recuperação conservacionista de superficies mineradas; uma revisão de literatura. Sociedade de investigações florestais. 51p. (Boletim técnico, 2). Universidade Federal de Viçosa, Viçosa.

MUELLER-DOMBOIS, D. \& H. ELLENBERG. 1974. Aims and Methods of Vegetation Ecology, J. Willey, New York.

PFADENHAUER, J.S. \& S. WINKLER. 1979. Estudos sobre a problemática ecopaisagística das áreas de deposição de rejeitos de mineração. In: Universidade Federal do Rio Grande do Sul \& Fundação de Amparo a Tecnologia e ao Meio Ambiente. Relatório Final Convênio FATMA-UFRGS. C. 10, p. 241-269, Porto Alegre.

PILLAR, V. de P. 1988. Fatores ambientais relacionados à vegetação de um campo natural. 120 fs. Dissertação (Mestr. Agron. - Fitotecnia). Fac. Agron./ UFRGS, Porto Alegre.

RUFFNER, J.D. \& W.W. STEINER. 1973. Evaluation of plants for uses on critical sities. In: Hutnik, R.J. \& Davis, G. (eds.), Ecology and Reclamation of Devastated Land. v. 2, p. 3-12. Gordon-Breach, New York.

TYSON, W. 1979. The native regrowth method for steep slopes. Landscape Architecture, Lou isville, 1: 57-61.

WILD, O. \& L. ORLOCI. 1983. Management and Multivariate Analysis of Vegetation Data. Berlin. 